\title{
Failure Impact Assessment for Large-Scale Landslides Located Near Human Settlement: Case Study in Southern Taiwan
}

\author{
Ming-Chien Chung ${ }^{1}$, Chien-Hsin Chen ${ }^{1}$, Ching-Fang Lee ${ }^{2, *}$, Wei-Kai Huang ${ }^{2}$ and \\ Chih-Hao Tan ${ }^{1}$ \\ 1 Geotechnical Engineering Research Center, Sinotech Engineering Consultants, Inc., Taipei 114, Taiwan; \\ mcchung@sinotech.org.tw (M.-C.C.); chchen@sinotech.org.tw (C.-H.C.); chtan@sinotech.org.tw (C.-H.T.) \\ 2 Disaster Prevention Technology Research Center, Sinotech Engineering Consultants, Inc., Taipei 114, Taiwan; \\ wuangwk@sinotech.org.tw \\ * Correspondence: cflee@sinotech.org.tw; Tel.: +886-2-8791-9198 (ext. 344)
}

Received: 16 March 2018; Accepted: 7 May 2018; Published: 9 May 2018

\begin{abstract}
In 2009, Typhoon Morakot caused over 680 deaths and more than 20,000 landslides in Taiwan. From 2010 to 2015, the Central Geological Survey of the Ministry of Economic Affairs identified 1047 potential large-scale landslides in Taiwan, of which 103 may have affected human settlements. This paper presents an analytical procedure that can be applied to assess the possible impact of a landslide collapse on nearby settlements. In this paper, existing technologies, including interpretation of remote sensing images, hydrogeological investigation, and numerical analysis, are integrated to evaluate potential failure scenarios and the landslide scale of a specific case: the Xinzhuang landslide. GeoStudio and RAMMS analysis modes and hazard classification produced the following results: (1) evaluation of the failure mechanisms and the influence zones of large-scale landslides; (2) assessment of the migration and accumulation of the landslide mass after failure; and (3) a landslide hazard and evacuation map. The results of the case study show that this analytical procedure can quantitatively estimate potential threats to human settlements. Furthermore, it can be applied to other villages and used as a reference in disaster prevention and evacuation planning.
\end{abstract}

Keywords: large-scale landslide; failure impact assessment; GeoStudio; RAMMS; Xinzhuang Village

\section{Introduction}

Slope-land disasters include large-scale landslides, the burial of villages, landslide dams, the destruction of roads and bridges, river scouring and aggradation, and mass transport of woody debris and sediment. In 2009, Typhoon Morakot passed over Taiwan, releasing over $2000 \mathrm{~mm}$ of rain in a 3-day period and triggering severe slope-land disasters in the south central and eastern parts of Taiwan. Typhoon Morakot caused over 680 deaths and more than 20,000 landslides in Taiwan. Given the danger of landslides, it is important to understand complex, large-scale landslides that have the potential to affect extensive areas in Taiwan.

The definition of a large-scale landslide often includes factors such as materials, landslide scale (depth, area, or volume), or type of movement [1-5]. In Taiwan, the current agreed-upon definition for a large-scale landslide is a landslide that is larger than $100,000 \mathrm{~m}^{3}$ in volume [5-7]. The large volume of material mobilized in a large-scale landslide can trigger accessory phenomena such as debris flows and river damming. Transportation systems can be severed, and structures buried. Therefore, large-scale landslides pose a significant hazard to villages located nearby.

The National Science and Technology Center for Disaster Reduction (NCDR) [8] described simplified methods for evaluating and inspecting the safety of communities or villages subject to 
landslide hazards. Their methodology adopted aerial photographs to rapidly survey landslide-prone areas and identify historical landslide locations. This information can be used to define areas that are susceptible to repeated landslides. Disaster types and the extents of large-scale landslides are also included in this evaluation and are used to assess the related hazards to which the villages and communities are subject. Additionally, through a long-term project implemented by the Central Geological Survey (CGS) $[9,10]$, the locations of potential large-scale landslides and the villages most susceptible to the related hazards have been mapped.

Although each of the participating agencies is rapidly working to identify villages exposed to potential large-scale landslide hazards within their jurisdictions, a standardized and appropriate method for performing such an investigation has yet to be developed. Therefore, this paper presents an analytical procedure that can be applied to assess the possible impact of a landslide collapse on nearby settlements. The aims of the paper are as follows: (1) to integrate existing survey techniques and analysis models; (2) to use GeoStudio software [11] and RAMMS-avalanche modeling software [12] to estimate the failure mechanism and influence zone of a large-scale landslide, assess the migration and accumulation of failure, and draw a landslide hazard map and an evacuation map; and (3) to contribute to the literature on landslide disaster prevention and evacuation planning.

\section{Methodology}

The flow chart for investigating and evaluating large-scale landslides is shown in Figure 1. The applied methodology includes two phases and five steps. The purpose of the investigation phase is to understand the environmental conditions affecting the failure behavior of the landslide, the infrastructure and the people at risk, the extent of the landslide body (including information on the location, shape and number of sliding masses) and the volume (including the area and thickness). Landslide investigations often include the acquisition and interpretation of remote sensing images, as well as hydrogeological investigation and tests. The purpose of the assessment phase is to understand the current stability of the sliding mass and the effects of external forces, such as earthquakes and precipitation, on the stability of the landslide, the mobilization of the landslide and the extent of the landslide runout. The goals of the assessment are to (1) extrapolate on the results of the site investigation to create a hydrogeological conceptual model of the landslide; (2) incorporate the hydrogeological conceptual model in a slope stability analysis; and (3) evaluate the influence zone of the landslide. In the following sections, each of these steps will be addressed. 

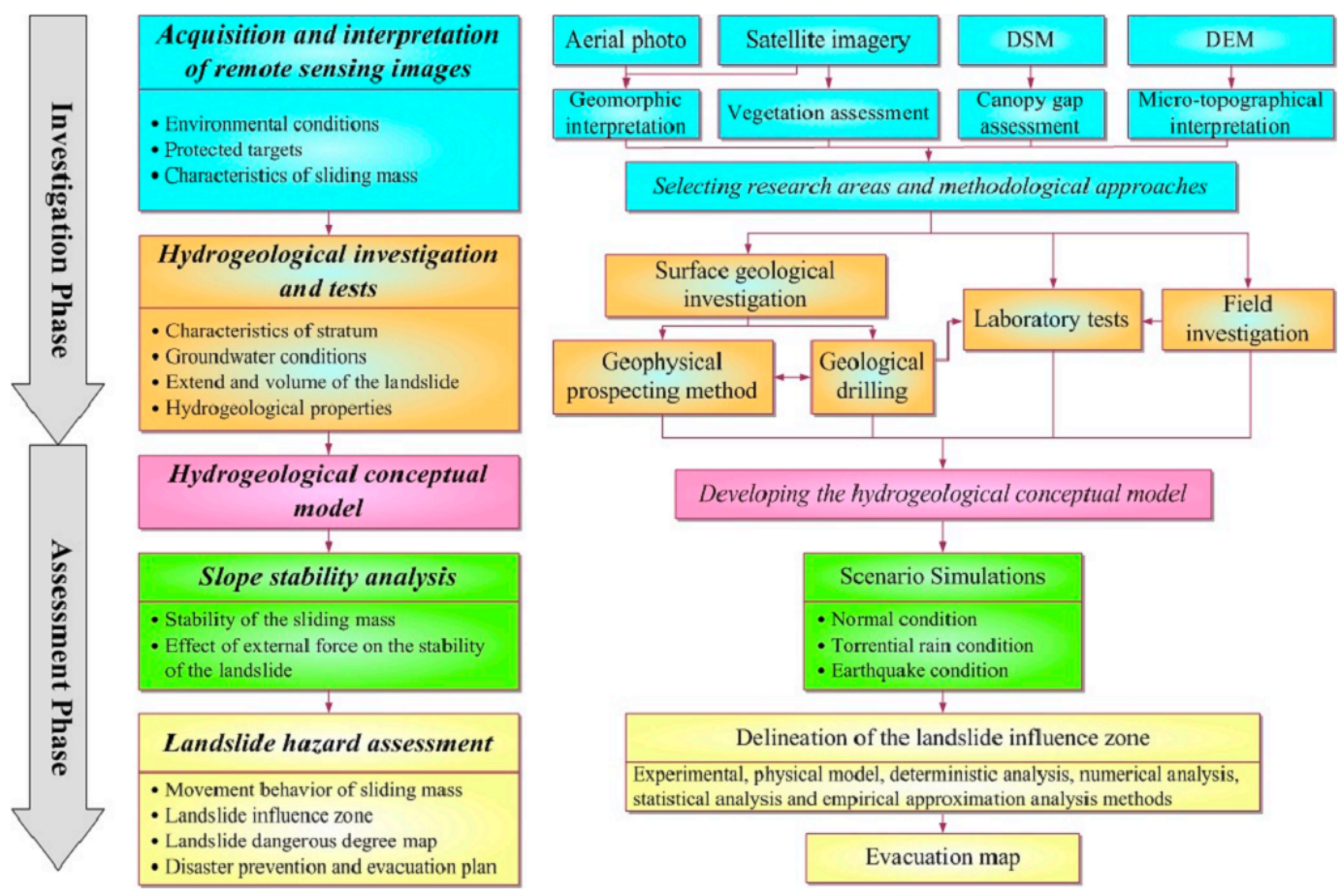

Figure 1. Investigation and assessment flow chart for a large-scale landslide.

\subsection{Acquisition and Interpretation of Remote Sensing Images}

Remote sensing images can be interpreted to understand the landform evolution of the study area and to verify the interpretation results. Image analysis methods are described in Bichler et al. [13], Booth et al. [14], Lahousse et al. [15], Hölbling et al. [16], and Lee et al. [17]. For our methods of interpretation, the study referred to CGS [18] for the topographic characteristics of deep-seated landslides and large-scale landslides (Figure 2), such as the scarps, crown tension fractures, side fissures, break lines, erosion gullies, bulging slope toes, or sliding masses $[4,19]$.

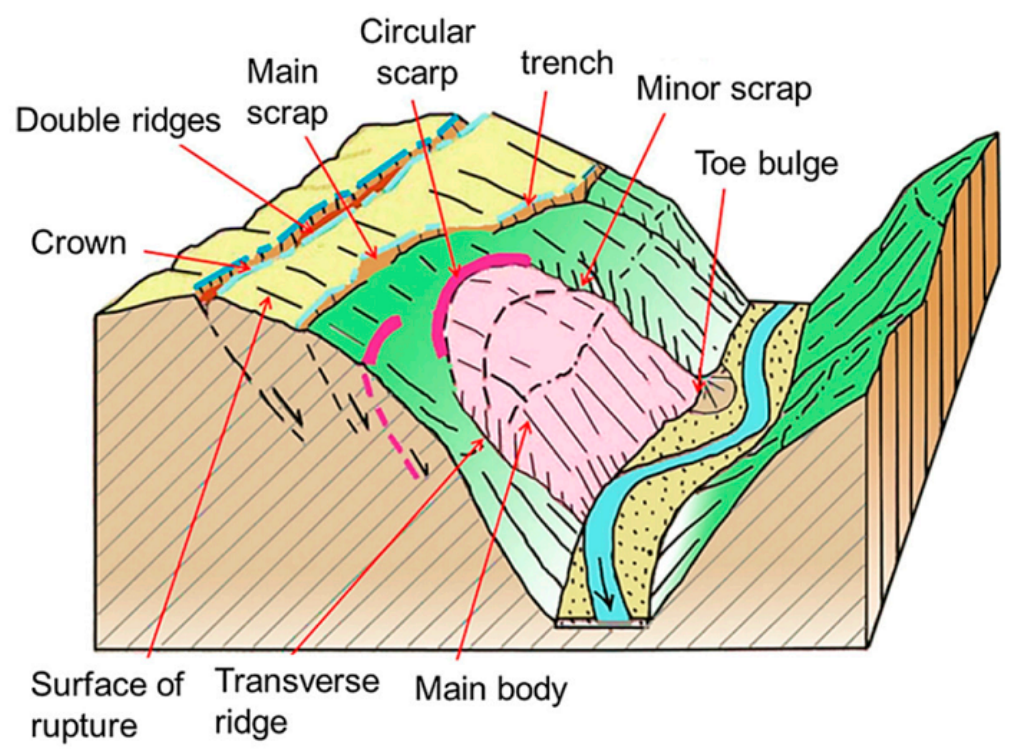

Figure 2. Active landslide geomorphic evolution and deep-seated landslide characteristics. 
Remote sensing images can also be interpreted to understand environmental conditions, the locations of infrastructure and people, and temporal changes in the landscape. After the sediment-related disaster of Typhoon Morakot, the Central Geological Survey launched a project entitled "Investigation and analysis for the geologically sensitive area in national preservation domain program", which ran from 2009 to 2015 . This national program adopted the wide-range airborne LiDAR technique to generate DEMs of $1 \mathrm{~m}$ spatial resolution in metropolitan and mountainous areas covering the whole of Taiwan. The corresponding mean cloud density in alpine zones is at least 2 points $/ \mathrm{m}^{2}$. All of the produced LiDAR derivatives, such as DEM, are separated into individual map sheets with a scale of 1:5000 for regional geohazard assessment. To clarify the extent of the failure mass, a high-accuracy digital elevation model (DEM) can be used to interpret the micro-topography of the landslide on the meter scale. High-resolution LiDAR DEMs with 1-m resolution of the entire island of Taiwan are available from the CGS. Additionally, the National Land Surveying and Mapping Center also provides 5-m resolution DEMs, digital surface models (DSMs), and ortho-corrected aerial photos. The micro-topography of landslides is generally interpreted from a DEM with the vegetative cover and man-made structures removed [4,5,19-21]. The extent of the possible landslide body is approximated from topographic characteristics, such as the main scarp and landslide body, found around landslides. Currently, this method is an important technique for interpreting the locations of large-scale landslides $[4,5,19]$. Landslide micro-topography interpretation is an approach that maps the small landform features of recent and ancient landslides on the meter scale. The classic deep-seated landslide characteristics on a hillslope can be seen in Figure 2. In this approach, corresponding slope, aspect, contour, and hillshading maps are first created from the DEM data, and then experts manually map all the landslide features (i.e., main scarp, landslide body, toe, gully, tension crack, and lateral boundary) to highlight the existing and potential hazard areas [22].

All of these topographic and movement characterizations are used to extract landslides from LiDAR products using an expert-based interpretive approach. Moreover, other topographic criteria, such as discordant vegetation observable, surface fissures, lateral flanks, oblique flows, and toe bulges in remote sensing observations of landslides, are also taken into consideration [17]. From the results of this analysis, the locations of terrain having characteristics indicative of slope instability can be used to demarcate the locations of potential sliding masses and estimate the potential hazard areas.

\subsection{Hydrogeological Investigations and Tests}

Remote sensing interpretation can be used to evaluate the environmental conditions affecting a landslide, the infrastructure and people located nearby, and the size of the landslide mass. However, more than one landslide mass may be present within the landslide body, and the specifics of each landslide mass must be re-evaluated through hydrogeological investigation and laboratory testing. Chung et al. [23] organized typical hydrogeological investigation methods as follows: (1) geological drilling, (2) surface geological investigation, (3) double-ring infiltration test [24], (4) geophysical prospecting method $[25,26],(5)$ borehole televiewer and logging $[27,28],(6)$ double packer test $[28,29]$, (7) pressure plate test [30], and (8) laboratory tests. Each investigative technique and its application is listed in Table 1. The above-mentioned techniques and the construction of a hydrogeological conceptual model of the landslide to understand the hydrogeological characteristics of each layer in the landslide can be used to understand the size of the sliding mass and to design a proper monitoring system. 
Table 1. Purposes and applications of hydrogeological investigation and tests (from Chung et al. [23]).

\begin{tabular}{cl}
\hline \multicolumn{1}{c}{ Method } & \multicolumn{1}{c}{ Purpose and Application } \\
\hline \multirow{2}{*}{ Geological drilling } & 1. Geological structure and mapping; \\
& $\begin{array}{l}\text { 2. Hydrogeological properties of numerical analysis; } \\
\text { 3. The potential slip surface of the landslide. }\end{array}$ \\
\hline Surface geological investigation & 1. Topographic and geologic features. \\
\hline \multirow{2}{*}{ Double-ring infiltration test } & 1. Infiltration rate of colluvium; \\
& 2. Hydrogeological properties of numerical analysis. \\
\hline \multirow{2}{*}{ Geophysical prospecting method } & 1. The potential slip surface of the landslide; \\
& 2. Aquifer characteristic and geological features. \\
\hline \multirow{2}{*}{ Borehole televiewer and logging } & 1. Borehole image and geological features; \\
& $\begin{array}{l}\text { 2. Strikes and dips of geologic features; } \\
\text { 3. Collection and interpretation of core samples. }\end{array}$ \\
\hline \multirow{2}{*}{ Double packer test } & 1. Hydraulic conductivity of rock mass; \\
& 2. Aquifer characteristic of landslide. \\
\hline \multirow{2}{*}{ Pressure plate test } & 1. Soil-water characteristic curve of colluvium; \\
& 2. Hydrogeological properties of numerical analysis. \\
\hline Laboratory tests & 1. Hydrogeological properties of numerical analysis. \\
\hline
\end{tabular}

\subsection{Developing the Hydrogeological Conceptual Model}

The objective of developing the hydrogeological conceptual model is to incorporate field data into an efficient and representative model that simplifies actual subsurface conditions. The development process includes (1) identifying the extent of the analysis area: defining all regions of concern in the study area, including the extent of the failure mass and the area impacted by the failure; (2) identifying hydrogeological units: using the spatial distribution of the strata/beds and differences in permeability to group layers that have similar hydrogeological properties into a single hydrogeological unit; (3) selecting parameters: treating each hydrogeological unit separately and selecting parameters that define the properties of each unit. Table 1 lists the investigation and laboratory test results that are used to identify parameters; (4) setting boundaries and initial conditions: setting as boundary conditions the surface and subsurface features identified in the field, including ridge lines, valleys, rivers, and drainage structures, and using piezometric records to establish the initial conditions and define the upper boundary of the water table; and (5) calibrating the model: adjusting the parameters of the model until predictions match observations. The use of a properly calibrated model increases confidence that the analysis results are representative of actual conditions. Methods used to calibrate parameters include trial and error and automated parameter estimation.

\subsection{Slope Stability Analysis}

The stability of slopes is judged based on a computed safety factor [31-35], an assessment of slope deformation [36], or a partial safety factor [37]. Most of the computer programs used for slope stability analysis are based on the limiting equilibrium approach for a two-dimensional model [38]. The safety factor is used to evaluate how heavy precipitation affects the water table and stability of a slope and how earthquakes affect the stability of the slope. Under different specifications and conditions, the requirements for the safety factor depend on relevant government authorities. Commonly, safety factors are computed for normal, torrential rain (high water table), and earthquake conditions. Moreover, the purpose of the partial safety factor method is to include the effects of external loads and environmental factors. The variability and uncertainty of those loads are incorporated into the analysis. The results of the evaluation provide an estimate of the effects on the stability of the slope. Finally, for especially important cases, or situations where the spatial variability of the layers is extremely large, both a reliability analysis and a sensitivity analysis of the parameters are performed. 
The method in this study uses GeoStudio software, produced by GEO-SLOPE International Ltd., to perform slope stability analysis of a two-dimensional model of the landslide. In the GeoStudio software, the SEEP/W module (finite element analysis module) and SLOPE/W module (limit equilibrium method module) are used. In the SEEP/W module, rainfall infiltration and groundwater flow are simulated. Based on Darcy's law, the governing equation is given as:

$$
\frac{\partial}{\partial x}\left(k_{x} \frac{\partial H}{\partial x}\right)+\frac{\partial}{\partial y}\left(k_{y} \frac{\partial H}{\partial y}\right)+Q=\frac{\partial \theta}{\partial t}
$$

where $H$ is total head; $k_{x}$ is hydraulic conductivity in horizontal direction; $k_{y}$ is hydraulic conductivity in vertical direction; $Q$ is applied boundary flux; $\theta$ is volumetric water content; and $t$ is time.

SEEP/W can be used to model both saturated and unsaturated flows under steady-state and transient conditions. Flux sections are used to determine the infiltration rate in the modeled slope. The steady-state seepage analysis is based on steady state seepage flow rates and normal water tables. The transient state seepage analysis uses the rainfall hygrograph to determine the initial boundary of the infiltration and simulate the variation in water table level for each time step.

The SLOPE/W module is used for stability analysis. Since much of the modeled slope is unsaturated, the safety factor computed by SLOPE/W is based on a Mohr-Coulomb modified equation suggested by Fredlund et al. [39]. Changes in pore-water pressures and their subsequent effect on the safety factor of the slope are quantified. The SEEP/W module transient analysis results of pore-water pressure conditions at various points along the slope are input into the SLOPE/W module allowing highly irregular saturated/unsaturated conditions or transient pore-water pressure conditions to be included in the stability analysis. This in turn permits the prediction of changes in stability with time.

\subsection{Delineation of the Landslide Impact Zone}

The methods used to delineate the landslide impact zone include experimental, physical model, deterministic analysis, numerical analysis, statistical analysis and empirical approximation analysis methods [40-43]. As technology and numerical modeling techniques have improved, the stability of each failure type, whether it is a rock fall, debris slide or rock slide, can be evaluated using modeling software [44]. Numerical models incorporated into the modeling software effectively model topography effects on landslides and the trajectory of sliding masses. For large-scale landslides, modeling software can be used to improve the accuracy and reliability of landslide hazard zonation. Notably, although many numerical models and commercial modeling software options are currently available, most models or software are often limited to specific modeling scenarios. Therefore, the sliding mechanism and parameters derived from geologic investigation of the landslide must be used to select an appropriate modeling program.

The method in this study uses RAMMS, which is a reliable numerical simulation tool yielding runout distance, flow heights, flow velocities and impact pressure of hillslope landslides and debris flows, to simulate the movement behavior after slope failure [12]. RAMMS adopts the Voellmy-Salm continuity model as a rheology assumption $[45,46]$. In this model, $x$ and $y$ depict the plane coordinates of a moving mass along the terrain surface, and the corresponding height along the normal line of an arbitrary point is defined as $z(z, y) \cdot g=\left(g_{x}, g_{y}, g_{z}\right)$, and $t$ represents the acceleration vector of 3-D gravity and time. RAMMS calculates flow depth $(H(x, y, t))$ and averaged velocity $(U(x, y, t))$ eigenvalues, while the moving mass is under the unsteady and non-uniform regimes. Both initial deposition depth and area of source area in the upstream reach can be derived from the manual interpretation on the GIS platform. The mass balance equation of Voellmy-Salm model is given below:

$$
\partial_{t} H+\partial_{x}\left(H U_{x}\right)+\partial_{y}\left(H U_{y}\right)=Q(x, y, t)
$$


where $U_{x}$ and $U_{y}$ are the moving velocities on the $x$ and $y$ axes; $Q(x, y, t)[\mathrm{m} / \mathrm{s}]$ is called the entrainment rate $(Q>0)$ or deposition rate $(Q<0)$. Depth-averaged momentum balance equations for the $x$ and $y$ axes are defined as

$$
\begin{gathered}
\partial_{t}\left(H U_{x}\right)+\partial_{x}\left(c_{x} H U_{x}{ }^{2}+\mathrm{g}_{z} \mathrm{k}_{\mathrm{a} / \mathrm{p}} \mathrm{H}^{2} / 2\right)+\partial_{y}\left(H U_{x} U_{y}\right)=S_{g x}-S_{f x} \\
\partial_{t}\left(H U_{y}\right)+\partial_{y}\left(c_{y} H U_{y}{ }^{2}+g_{z} k_{a / p} H^{2} / 2\right)+\partial_{x}\left(H U_{x} U_{y}\right)=S_{g y}-S_{f y}
\end{gathered}
$$

where $c_{x}$ and $c_{y}$ are shaped factors depending on topography; $k_{a / p}$ is the coefficient of earth pressure; $S_{g x}$ and $S_{g y}$ depict the terms of gravity acceleration; and the frictional terms along the $x$ and $y$ axes are specified as $S_{f x}$ and $S_{f y}$.

\section{Case Study}

\subsection{Study Area}

The CGS [10] concluded that a potential large-scale landslide in the Xinzhuang Village of Shanlin District, Kaohsiung City (Figure 3a), may impact the safety of adjacent infrastructure and Xinzhuang Village (ID: Kaohsiung-Shanlin-D021, herein called the Xinzhuang landslide). According to census data from March from the household registration office of Kaohsiung City, Shanlin District, Xinzhuang had a total of 724 households and 1760 people. The primary transportation routes that connect Xinzhuang with outside areas are Highway 29 and County Road 181. Highway 29 is an east-west highway that connects Jiaxian and Cishan Districts. County Road 181 connects Xinzhuang to the Meinong District in the south.

The Xinzhuang landslide is located on Shizi Mountain near Xinzhuang Village (Figure 3b). It also lies above the Neiying thrust fault of the northern section of the Chishan fault, according to the geological survey. As shown in Figure 4, the complex series of geological features in the Xinzhuang landslide-prone area are mainly composed of metamorphic and sedimentary rocks and classified into two categories: (1) upper hillslope: alternations of sandstone and shale formations (high sand content); and (2) lower hillslope: shale formations (high silt content). Furthermore, the soil material of the part region around the gully at the downslope reach reveals that it mostly consists of a weathering deposition layer. The regional attitude of the bedding plane along the study area is approximately $\mathrm{N} 30^{\circ} \mathrm{E} / 40^{\circ} \mathrm{NW}[47,48]$. However, the orientation of the bedding plane in the downslope region exhibits a disturbance condition due to sliding behavior in the past. The area of the landslide is 10.3 ha $\left(1.03 \times 10^{5} \mathrm{~m}^{2}\right)$. The elevation of the landslide ranges from $210 \mathrm{~m}$ to $418 \mathrm{~m}$, while the horizontal length of the landslide is $520 \mathrm{~m}$ (Figure 3c). Several residents live more than $230 \mathrm{~m}$ from the landslide toe (Figure $3 \mathrm{~b}$ ). The higher slopes are found near the ridge line and at the landslide toe, where the slope ranges from 35 to 70 degrees (Figure 3d). However, the average slope of the Xinzhuang landslide is 23 degrees. A large portion of the surface of the landslide has a northern aspect $(17.8 \%$, Figure 3e), and except for the west and southwest directions, the aspect is evenly distributed among the other directions. 


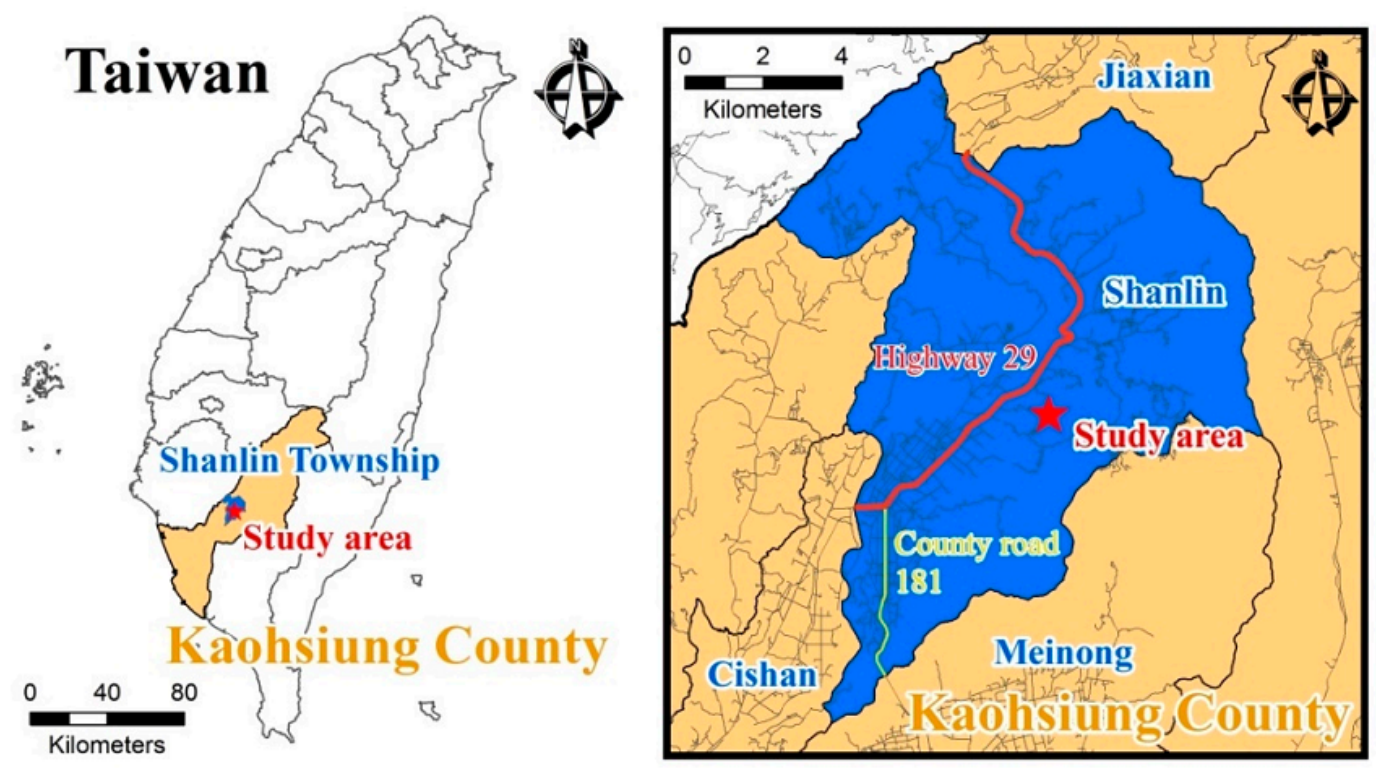

(a) Location of the Xinzhuang landslide in Kaohsiung, Taiwan

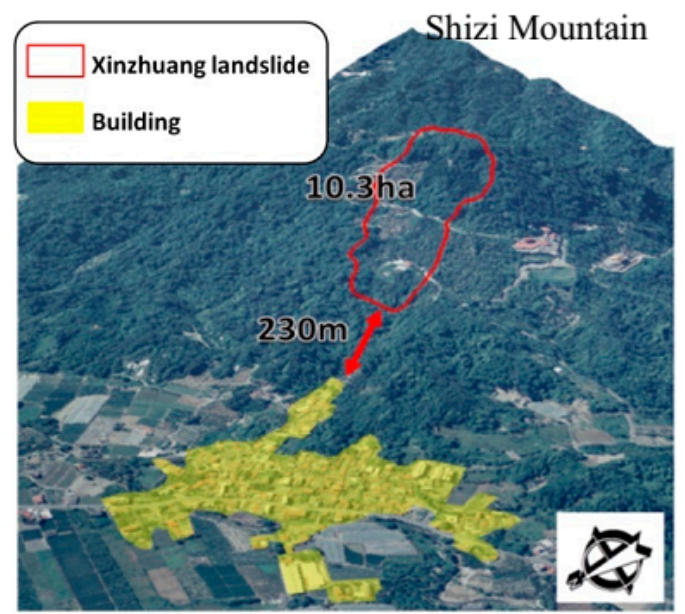

(b) Satellite image

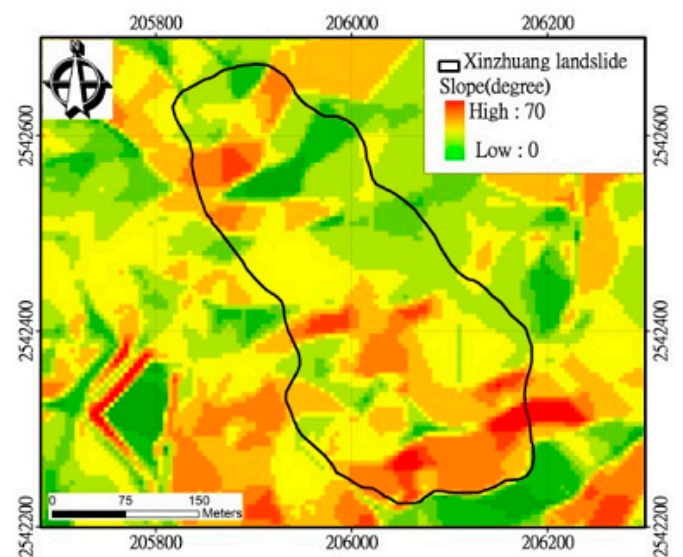

(d) Slope map

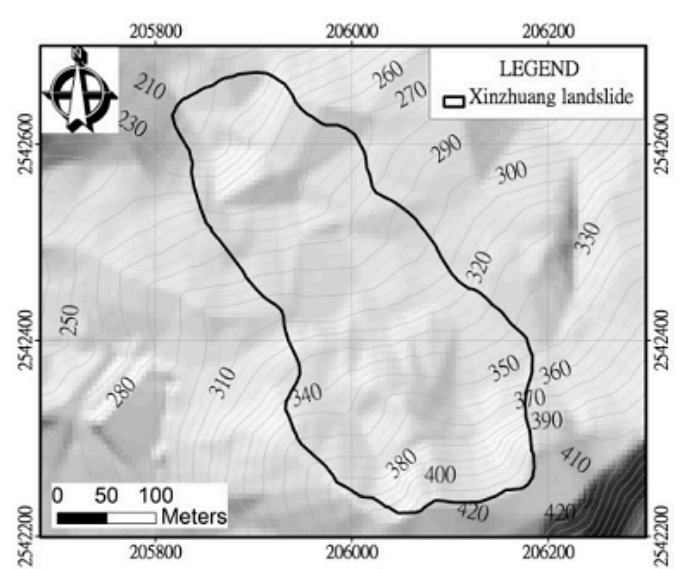

(c) Contour map

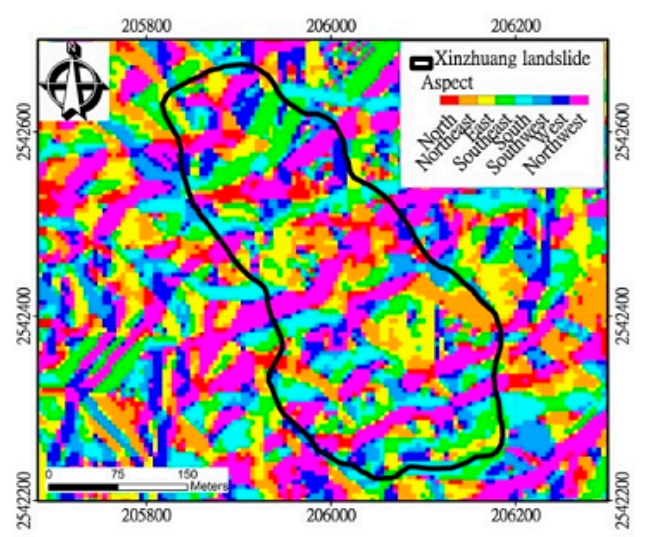

(e) Aspect map

Figure 3. Location and basic environmental conditions of the Xinzhuang landslide. (a) Location of the Xinzhuang landslide in Kaohsiung, Taiwan; (b) Satellite image; (c) Contour map; (d) Slope map; (e) Aspect map. 


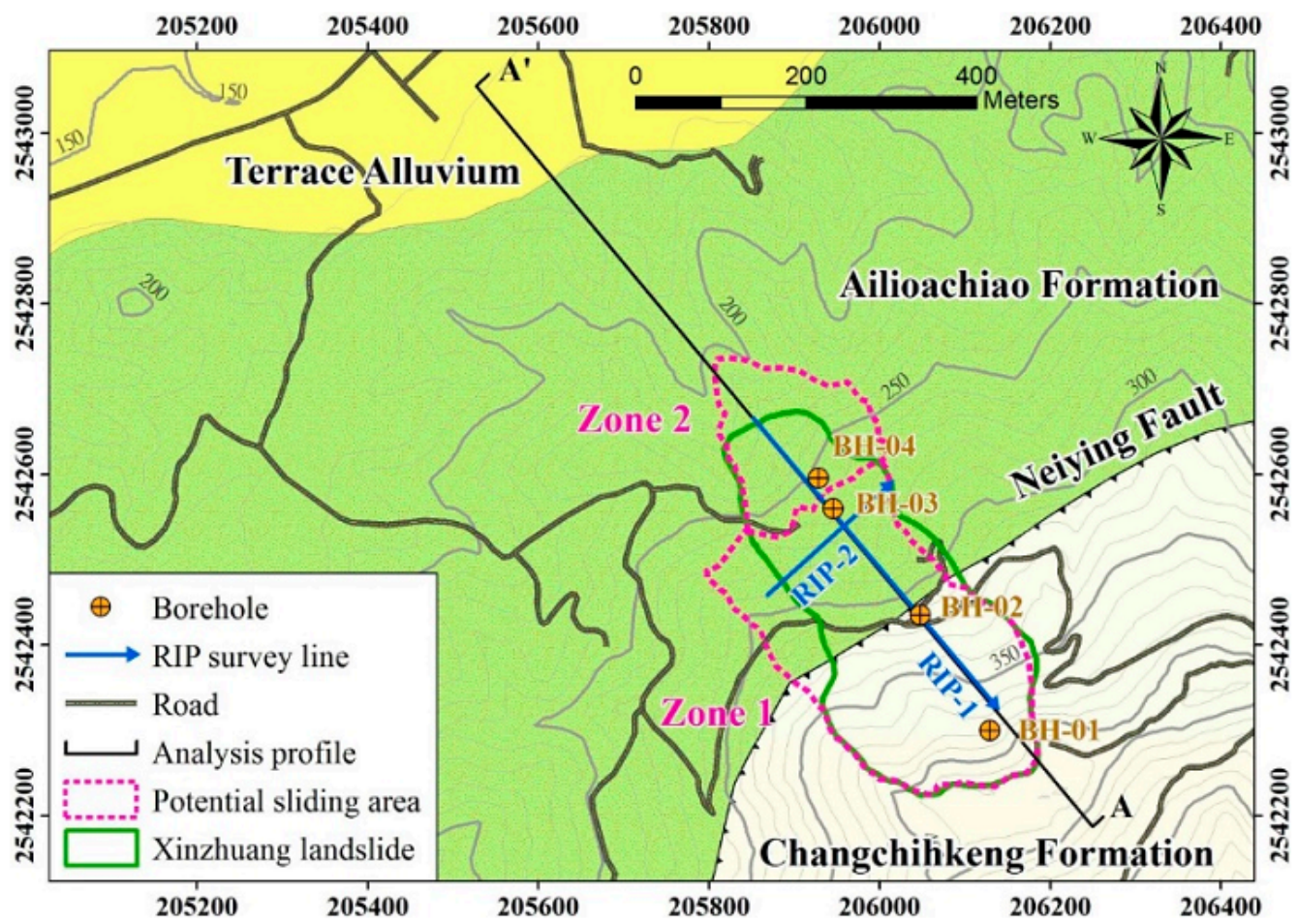

Figure 4. Geophysics and geologic borehole investigation locations.

Additionally, a scarp is located at the top of the slope. Because of the presence of the scarp (point 2 and point 3 in Figure 5; [49,50]), it was decided that an assessment of activity at the debris mass at the base of the scarp was necessary. As noted above, a large portion of the surface of the landslide has a northern aspect, and except for the west and southwest directions, the aspect is evenly distributed among the other directions. This highly complex surface morphology is evidence that the surface of the slope had been disturbed and is now reversing convex. Furthermore, there is an isolated topographic bulge caused by a build-up of mobilized material. This topographic signature was described in Soeters and van Westen [3] and resembles the hummocky relief they observed. All of this geomorphological evidence (Section 3.2) indicates that the Xinzhuang landslide moved at an earlier period of time. With regard to slope instability indicators, the location of potential sliding masses requires additional investigation. 

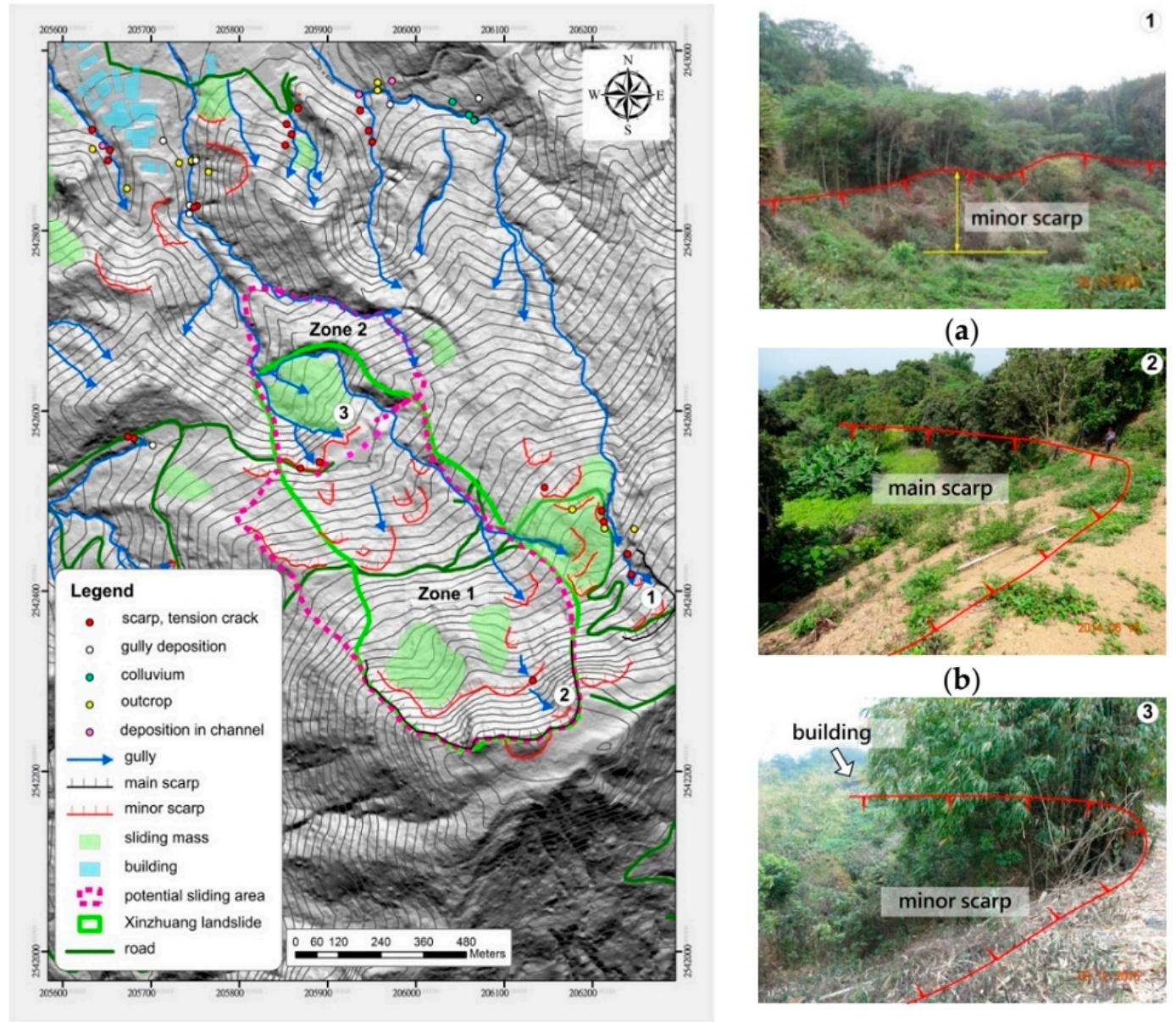

(a)

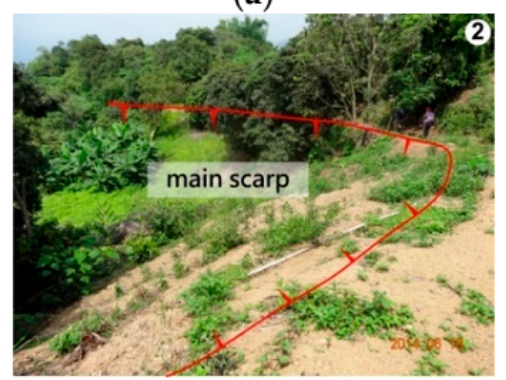

(b)

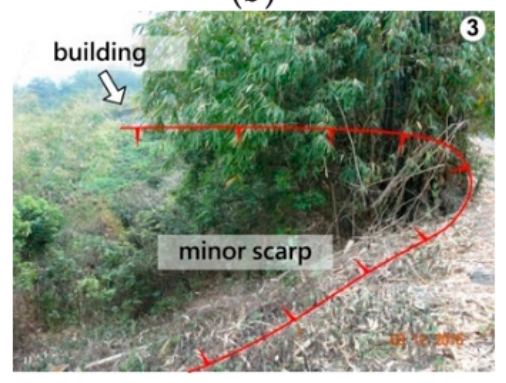

(c)

Figure 5. Results of micro-topography interpretation for the Xinzhuang landslide. (a) Minor scarp; (b) Main scarp; (c) Minor scarp.

\subsection{Geomorphological Interpretation}

With regard to the geohazard impact in the downslope reach, aerial photo and satellite images were further investigated using landslide micro-topography mapping by the CGS from aerial photos and DTM data. To ensure a high-detail survey and to fully grasp the potential large-scale landslide and adjacent areas of possible slope instability, the study also examined areas outside the large-scale landslide identified by the CGS, up to 230 to $1200 \mathrm{~m}$ from the survey area. The final extent of the study area included in our investigation is shown in Figure 5.

The landslide features used to delineate the hazard area included the main scarp (most of the steep cliffs formed by slope slumps are scarps of slope top failure. The flanks are the result of the steep slumps and can be used to gauge the strain rate of the slope failure process), the secondary scarp (minor scarp or depressed block) and any relict slumps defined by a sliding mass (the primary sliding body presents a dustpan-shaped depression with the upper section displaying subsidence), and gullies (the looseness of the soil increases permeability, which then enables micro-drainage system to develop parallel to the direction of the collapse after it rains) [50]. The average drop height of the main scarp is $6 \mathrm{~m}$, and the extension length of the main scarp is $440 \mathrm{~m}$. The study used these features to identify, check and re-delineate the sliding area of the Xinzhuang landslide. Based on landslide feature interpretation and field investigation results, the landslide can be divided into two potential sliding areas: Zone 1 and Zone 2. These zones are located up-slope (above point 2) and down-slope (above point 3 ) of the original hazard area (the area bounded by the solid green bold line) 
respectively. Based on the distribution of disturbed forest, the toe of the slope is more disturbed than the ridge. This finding indicates that the slope is unstable. The clearly identifiable scarp is mapped in Figure 5, but the landslide mechanism still needs to be confirmed. The large-scale landslide extent was therefore increased to include this scarp, which expanded the Xinzhuang landslide to include more of the upstream area (Zone 1) and the down slope area (Zone 2). The addition of these two areas only slightly increased the original area of the Xinzhuang landslide.

Inside the sliding areas (thick, dashed pink line), just down-slope of the main scarp (Zone 1), are currently two clear areas of accreted topography. In this study, these colluvial deposits or toe bulges (those leaning toward the scarp are associated with small-scale sliding masses, and the extrusion can result in a reduction in the cross-section of the creek; [50]) were interpreted as coming from the main scarp, having formed after a stress-caused deformation, failure and release of material. The speculated colluvial deposits located in the down slope part of the study area (Zone 2) are incised by gullies along the edges of the sliding mass. Near the upstream region of the study area, at the top of the slope on the north-eastern edge of the potential sliding mass, another obvious scarp (point 1) and an area of accreted topography are present; however, these landslide features are located beyond the scope of this study, as any movement is topographically directed away from the Xinzhuang Village infrastructure and residents. Therefore, these landslide features were not included in the study area. However, outside of the study area are other landslide features, such as obvious erosion gullies and scarps. These should also be mapped and monitored for use in understanding the topographic evolution of the area.

Within the study area, erosion gullies are well defined in the micro-topography. The gullies originated from scarp-like topography and can be traced from Xinzhuang Village to the upper reaches of the watershed. The rapidly formed and clearly defined gullies may indicate that the regolith is weathered, and the bedrock is highly fractured. This feature is the most prominent in the hilly topography within Xinzhuang Village. Outside of the study area, there are other areas of sporadic secondary scarps (step-like or steep cliff-like topography) and areas of bulges in the slope (landslide debris). All other areas are developed into fruit and tree plantations. Human activity, including the construction of the irrigation and transportation structures and subsurface closure of subsurface water sources, is also affecting the topography of the study area.

\subsection{Hydrogeological Investigations and Tests}

The method in this study uses surface geological investigation, geophysical prospecting (resistivity image profiling, RIP), geological drilling, and field and laboratory tests to identify the depth of, and the parameters that can be used to describe, the sliding mass. The layouts of the RIP method and geological drilling investigation in this study are shown in Figure 4. The RIP-1 survey line was located in the center of the Xinzhuang landslide, running parallel to the slope direction. RIP- 1 was $450 \mathrm{~m}$ long and was used to understand the hydrogeological conditions along the profile. The RIP-2 survey line was established running perpendicular to the slope of the landslide. It was $200 \mathrm{~m}$ long and was used to understand the hydrogeological conditions along the profile. The geological drilling investigation was established along the failure direction of the landslide. From top to bottom, the bore hole identification numbers were $\mathrm{BH}-01, \mathrm{BH}-02, \mathrm{BH}-03$, and $\mathrm{BH}-04$. The total borehole depth was $200 \mathrm{~m}$. The results of the borehole data were paired with geophysical observations to accurately interpret the subsurface conditions along RIP-1.

According to the surface geologic investigation and interpretation of borehole material, the hydrogeological unit at the Xinzhuang landslide was divided into the following 6 categories: colluvium [C]; fractured mudstone and sandy shale [M1]; intact mudstone and sandy shale [M2]; fractured alternations of sandstone (S.S.) and shale (Sh.) [S1]; intact alternations of S.S. and Sh. [S2]; and faulted rocks $[\mathrm{F}]$. The results of the geophysics survey and borehole interpretation along RIP-1 are shown in Figure 6a. 


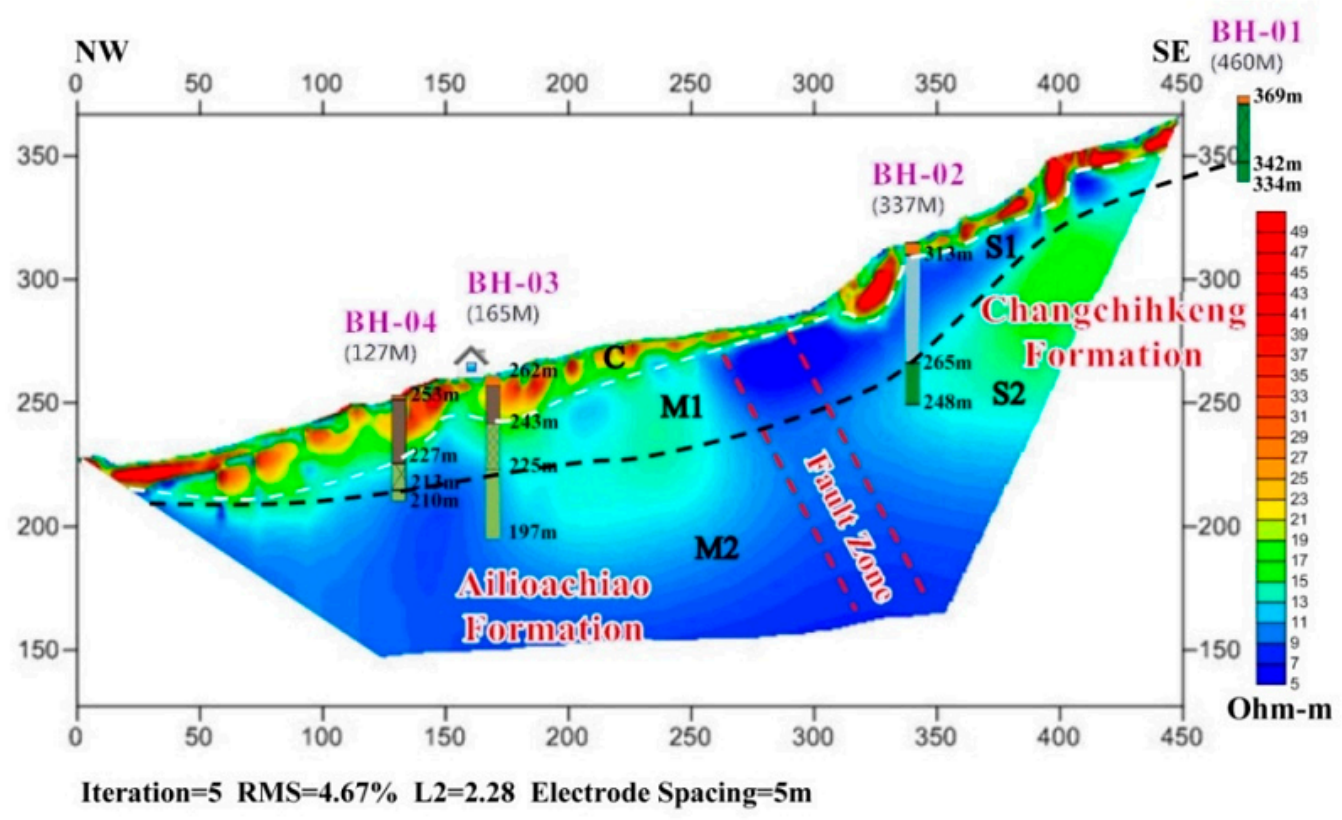

(a) RIP-1 survey line

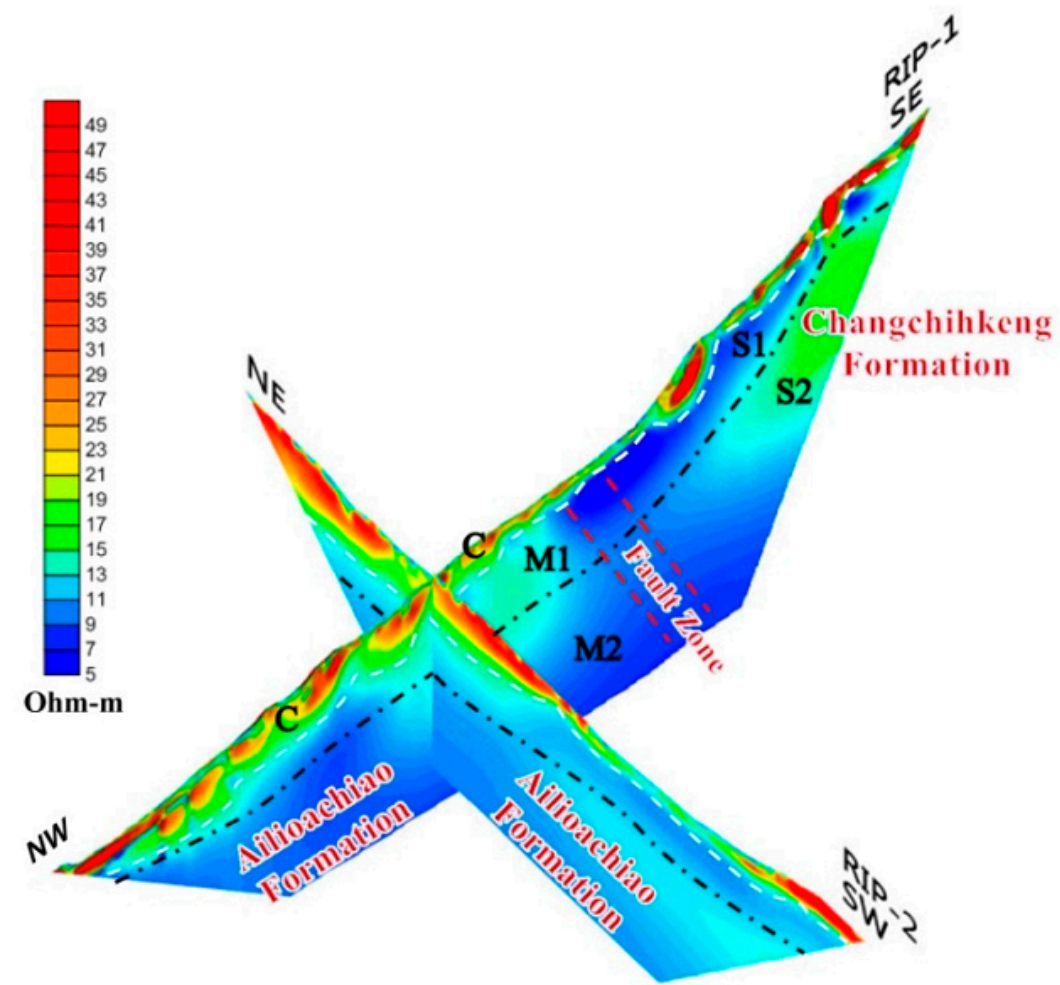

(b) RIP-1 and RIP-2 survey lines

Figure 6. Illustrations of geophysical and geologic borehole investigation results. (a) RIP-1 survey line; (b) RIP-1 and RIP-2 survey lines.

In the image, the contact between the colluvium and the in-place bedding is very clear (white dotted line). The thicker part of the colluvium is located at $90-130 \mathrm{~m}$ of the profile (thickness is approximately $30 \mathrm{~m}$ ). Comparing the geologic borehole data to the geophysics profile reveals clear contact between the Changchihkeng formation and the Ailioachiao formation, defined by a layer of highly fractured rock (black dotted line). This contact may be a slip surface (Table 2). It appears to 
underlie much of the study area, and in some areas, it is as deep as 48 meters below the surface. Using the results of geophysical exploration at RIP-2, a two-dimensional approximation of the subsurface conditions was created (Figure $6 \mathrm{~b}$ ) and used as a basis for another three-dimensional model of the landslide. The results of the hydrogeological investigation are summarized in a profile of the Xinzhuang landslide in Figure 7.

Table 2. Potential sliding surfaces and core photos.

\begin{tabular}{|c|c|c|c|}
\hline \multirow{2}{*}{ Borehole ID } & \multicolumn{3}{|c|}{ Potential Sliding Mass } \\
\hline & Zone 1 & Zone 2 & Zone 3 \\
\hline \multirow{2}{*}{ BH-01 } & $27.4-27.5 \mathrm{~m}$ & \multirow[b]{2}{*}{-} & $27.4-27.5 \mathrm{~m}$ \\
\hline & $9=25$ & & $8=-5=$ \\
\hline \multirow[b]{2}{*}{ BH-02 } & $39.4-39.5 \mathrm{~m}$ & \multirow[b]{2}{*}{-} & $47.8-48.0 \mathrm{~m}$ \\
\hline & 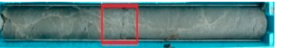 & & 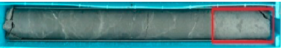 \\
\hline \multirow[b]{2}{*}{ BH-03 } & $19.9 \mathrm{~m}$ & \multirow[b]{2}{*}{ - } & $37.3-37.7 \mathrm{~m}$ \\
\hline & 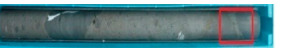 & & 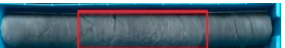 \\
\hline \multirow[b]{2}{*}{ BH-04 } & \multirow[b]{2}{*}{-} & $20.4-20.7 \mathrm{~m}$ & $36.2-36.8 \mathrm{~m}$ \\
\hline & & +2 & 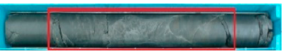 \\
\hline
\end{tabular}

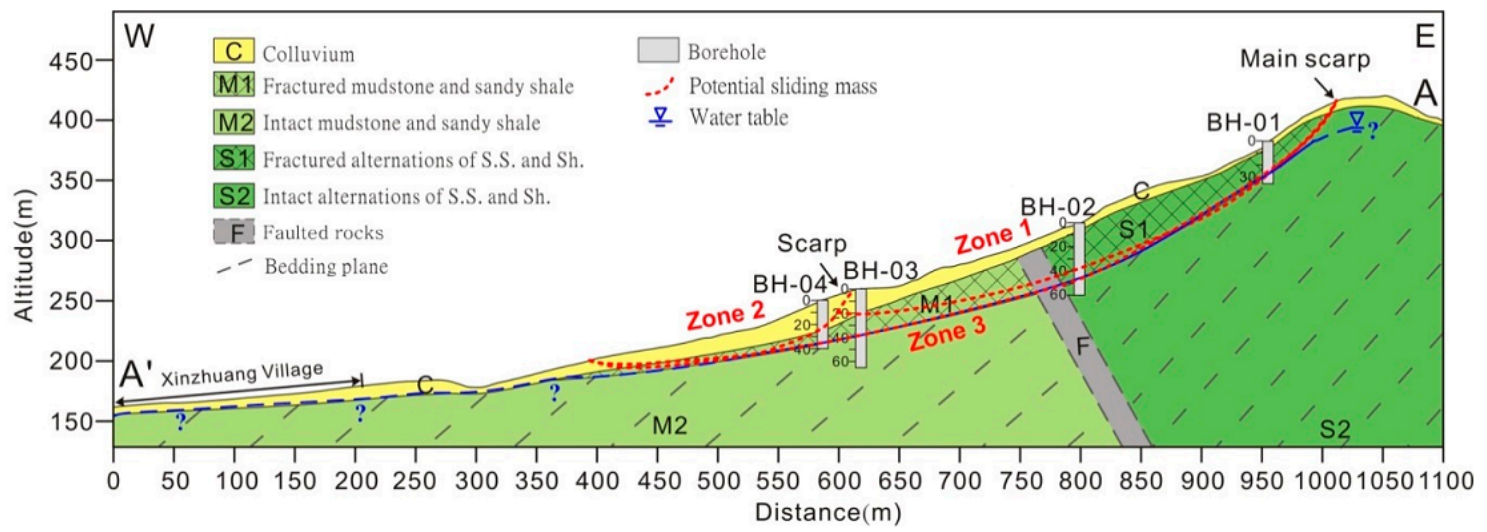

Figure 7. Geologic profile of the Xinzhuang landslide.

As indicated in Figure 7, the study area included the Changchihkeng formation and the Ailioachiao formation. These two formations consist of different materials and have different properties. BH-01 (35 m) and BH-02 $(60 \mathrm{~m})$ were located in the Changchihkeng formation in the upper slope. On the lower slope, BH-03 $(65 \mathrm{~m})$ and BH-04 $(40 \mathrm{~m})$ were located in the Ailioachiao formation. Based on laboratory test results, the strength of the Changchihkeng formation is higher than that of the Ailioachiao formation. The results of laboratory tests are presented in Table 3. 
Table 3. Laboratory test results for the Xinzhuang landslide.

\begin{tabular}{cccc}
\hline \multirow{2}{*}{ Type } & Property & $\begin{array}{c}\text { BH-01 and BH-02 } \\
\text { (Changchihkeng Formation) }\end{array}$ & $\begin{array}{c}\text { BH-03 and BH-04 } \\
\text { (Ailioachiao Formation) }\end{array}$ \\
\hline \multirow{4}{*}{ Colluvium } & Specific gravity & 2.71 & $2.70-2.71$ \\
& Unit weight $\left(\mathrm{t} / \mathrm{m}^{3}\right)$ & $1.69-1.81$ & $1.57-1.66$ \\
& Cohesion $\left(\mathrm{kg} / \mathrm{cm}^{2}\right)$ & 0.15 & 0.03 \\
& Friction angle $($ degree $)$ & 27.4 & 31.0 \\
\hline \multirow{5}{*}{ Fractured Rock } & Specific gravity & 2.67 & $2.66-2.68$ \\
& Unit weight $\left(\mathrm{t} / \mathrm{m}^{3}\right)$ & $2.60-2.61$ & $2.57-2.60$ \\
& Cohesion $\left(\mathrm{kg} / \mathrm{cm}^{2}\right)$ & 0.45 & 0.35 \\
& Friction angle $($ degree $)$ & 32.5 & 23.0 \\
\hline
\end{tabular}

Note: Specific gravity and unit weight were obtained from soil classification test. Cohesion and friction angle were obtained from direct shear test and unconfined compression test.

\section{Results and Discussion}

\subsection{Hydrogeological Conceptual Models}

The geological model was established using a $5 \mathrm{~m} \times 5 \mathrm{~m}$ Digital Elevation Model (DEM) of Xinzhuang village. The profile analyzed from the DEM is indicated by the line $\mathrm{AA}^{\prime}$ in Figure 5. The cross-section begins at the top of the ridge above the landslide, intersects with boreholes $\mathrm{BH}-01$, $\mathrm{BH}-02, \mathrm{BH}-03$, and $\mathrm{BH}-04$ and extends to the toe of the landslide. The model constructed in GeoStudio is shown in Figure 8. The boundary conditions of the hydrogeologic conceptual model are also shown in Figure 8. To analyze infiltration and seepage flow, the left side boundary (RA) was set as a no-flux boundary because a crest line had already been established. The right side boundary (SB) was set as a constant head boundary equal to the water table at the toe of the slope and adjacent drainage. The lower boundary (AB) was set as a no-flux boundary. The surface of the slope (RS) was then set as a rainfall-infiltration boundary.

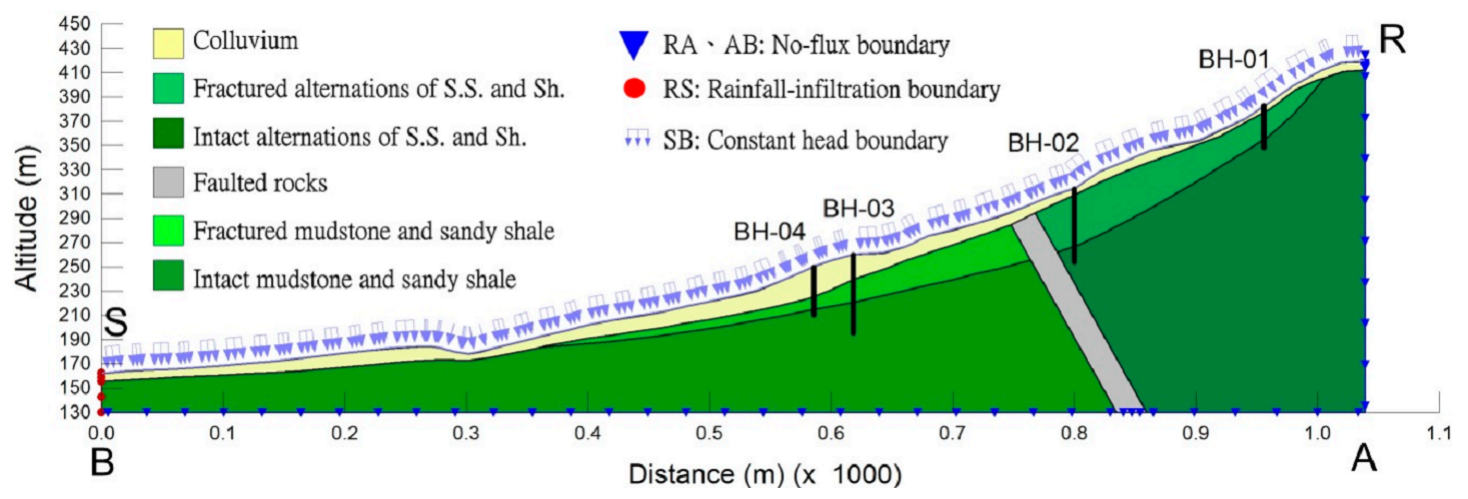

Figure 8. Numerical models of the Xinzhuang landslide.

Two observation wells (BH-01 and $\mathrm{BH}-03$ ) were set up in the Xinzhuang landslide. Based on borehole logging and monitoring results from the boreholes, the water table under normal conditions is located at the bottom of the fractured bedrock layer. Based on laboratory tests (Table 3) and monitoring results, the hydrogeologic parameters of each layer are organized in Table 4. Hydraulic parameters were calibrated by comparison with monitoring data and the results of steady-state seepage analysis. According to the steady-state seepage analysis, the value of the constant head on the left side (SB in Figure 8) is $156 \mathrm{~m}$ and the rainfall-infiltration boundary is $5 \mathrm{~mm} /$ day (unit flux). 
Table 4. Hydrogeologic parameters used in numerical model for the Xinzhuang landslide.

\begin{tabular}{|c|c|c|c|c|c|c|c|}
\hline \multirow{2}{*}{ Parameters } & \multicolumn{6}{|c|}{ Hydrogeologic Unit } & \multirow{2}{*}{ Data Sources } \\
\hline & C & M1 & M2 & S1 & S2 & F & \\
\hline $\begin{array}{l}\text { Unit weigh } \\
\left(\mathrm{kN} / \mathrm{m}^{3}\right)\end{array}$ & 18.1 & 25.8 & 25.8 & 26.0 & 26.0 & 26.0 & Soil classification test \\
\hline Cohesion $\left(\mathrm{kg} / \mathrm{cm}^{2}\right)$ & 0.09 & 0.35 & 3.50 & 0.45 & 4.50 & 0.00 & Direct shear test \\
\hline $\begin{array}{l}\text { Friction angle } \\
\text { (deg.) }\end{array}$ & 29.0 & 23.0 & 30.0 & 32.5 & 35.0 & 32.5 & $\begin{array}{l}\text { Direct shear test, Unconfined } \\
\text { compression test }\end{array}$ \\
\hline $\begin{array}{c}\text { Hydraulic } \\
\text { conductivity }(\mathrm{m} / \mathrm{s})\end{array}$ & $5.78 \times 10^{-4}$ & $1.39 \times 10^{-5}$ & $5.56 \times 10^{-9}$ & $6.94 \times 10^{-5}$ & $3.06 \times 10^{-8}$ & $5.78 \times 10^{-6}$ & $\begin{array}{l}\text { Back analysis (compare with } \\
\text { monitoring data) }\end{array}$ \\
\hline
\end{tabular}

\subsection{Slope Stability Analysis}

The setting of each scenario was as follows: (1) normal condition: the water table was obtained by steady-state seepage analysis, and the effect of seismic force was not considered; (2) torrential rain condition: the water table was obtained by transient seepage analysis, and the effect of seismic force was not considered. For the transient seepage analysis, the 20-year return period rainfall $(1076 \mathrm{~mm}$ in 3 days) was adopted as the rainfall infiltration boundary; (3) earthquake condition: the water table was obtained by steady-state seepage analysis and the seismic force was considered. The peak ground acceleration (PGA) was $0.28 \mathrm{~g}$ [51]. The stability of each sliding mass under normal, torrential rain, and earthquake conditions was evaluated in the analysis, and the results were used as a reference for evaluating the landslide hazard.

The initial conditions for the water tables of each scenario were based on the analysis results of steady-state seepage analysis by SEEP/W. The steady-state seepage analysis was based on the boundary conditions of the hydrogeologic conceptual model (Figure 8) and the hydrogeologic parameters of the Xinzhuang landslide (Table 4) to assess the water table, shown as Figure 9a. In SEEP/W, rainfall events are simulated by inputting a unit flux value along the rainfall infiltration boundary. For the torrential rain condition, the water table obtained by transient seepage analysis is shown in Figure 9b. A comparison of Figure 9a,b shows a significant rise in the water table. The water table of the upper slope rises to nearly the bottom of the Colluvium, and it rises above the bottom of the Colluvium in the down slope. Furthermore, the safety factor of the Xinzhuang landslide was assessed for various conditions by entering the rainfall infiltration boundary or PGA into the verified model.

Based on Figure 7, this study speculates that two types of failure mechanisms may drive the landslide. The first type is a failure involving multiple sliding masses: Zone 1 and Zone 2 are two different potential sliding masses and are treated separately. The second failure mechanism is a single sliding mass where Zone 1 and Zone 2 are part of the same sliding mass, shown as Zone 3 in Figure 7. The upper area of Zone 1 is the main scarp of the landslide. The upper area of Zone 2 is the secondary scarp. The area of Zone 3 includes all of the sliding masses, so the sliding surface is deeper. The safety factor of each scenario was based on the results of the slope stability analysis by SLOPE/W. Results are shown in Table 5. The results revealed that of the three failure planes, regardless of the location of the water table or the PGA, the safety factor was lowest for Zone 3. For earthquake conditions, the safety factor dropped under 1.2. Based on these findings, the study speculates that Zone 3 could become unstable if the PGA reaches $0.28 \mathrm{~g}$ (Figure 10). This study suggests that landslide hazard assessment of the Xinzhuang landslide focus on evaluating the stability of Zone 3. 


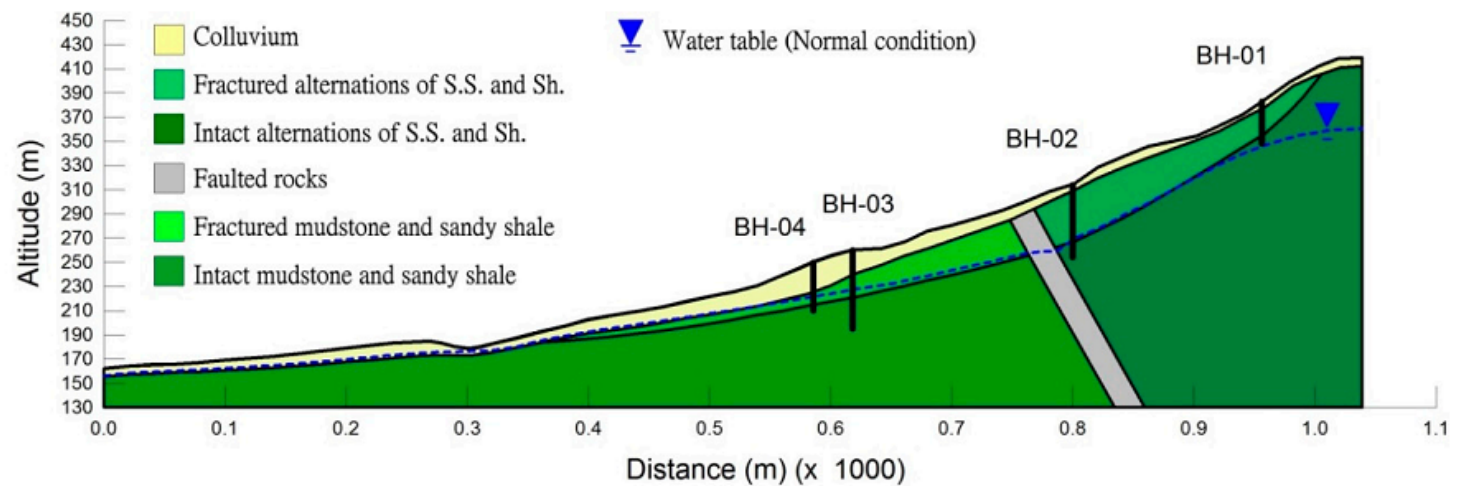

(a) Steady-state seepage analysis

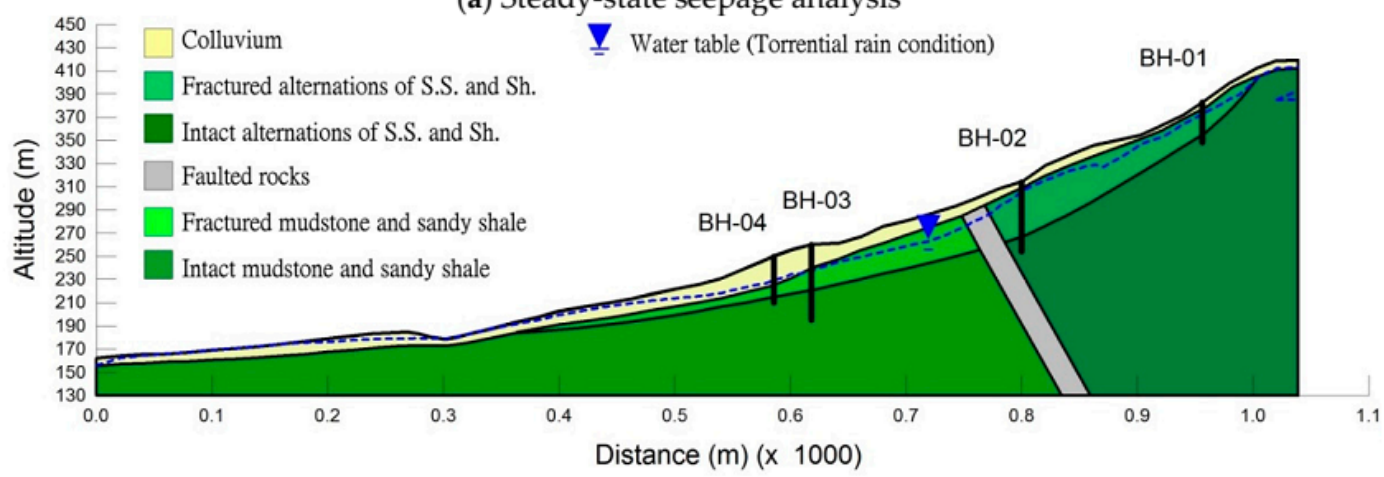

(b) Transient seepage analysis

Figure 9. Analysis results of seepage analysis under normal and torrential rain conditions. (a) Steady-state seepage analysis; (b) Transient seepage analysis.

Table 5. Safety factor obtained by slope stability analysis for the Xinzhuang landslide.

\begin{tabular}{ccccc}
\hline \multirow{2}{*}{ Scenario } & \multirow{2}{*}{ Minimum Requirement } & \multicolumn{3}{c}{ No. of Sliding Mass } \\
\cline { 3 - 5 } & & Zone 1 & Zone 2 & Zone 3 \\
\hline Normal condition & 1.50 & 1.73 & 1.99 & 1.61 \\
Torrential rain condition & 1.10 & 1.48 & 1.75 & 1.31 \\
Earthquake condition & 1.20 & 1.24 & 1.31 & 1.12 \\
\hline
\end{tabular}

Note: Minimum requirements extracted from Technical Regulations for Soil and Water Conservation [52]

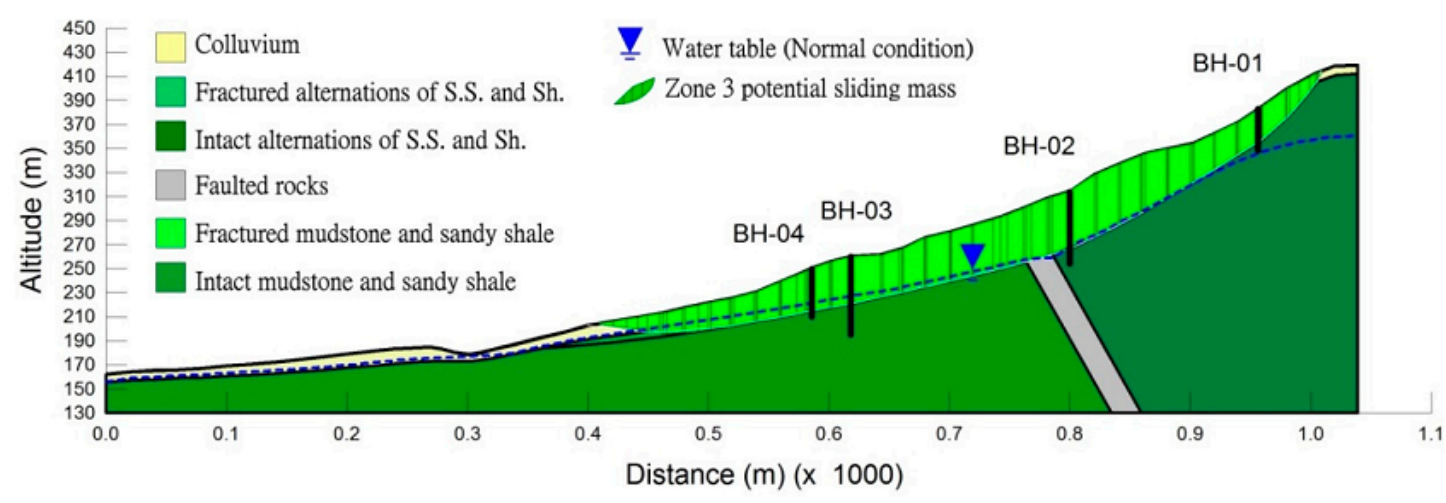

Figure 10. Analysis results of slope stability analysis under earthquake condition. 


\subsection{Landslide Impact Zone}

The RAMMS avalanche modeling software, which is commonly applied software for discrete element numerical modeling, was used to assess the impact of failure on Xinzhuang Village. RAMMS allows the user to import DEM data directly as an initial topography (before landslide) with a standard format (i.e., XYZ). The 1-m resolution DEM of the Xinzhuang landslide was converted to a 2-m resolution matrix of discrete elements (Figure 11) using the RAMMS modeling software. Parameters used in calibrating the model were taken from Table 4 . The parameters in Table 4 were developed from laboratory tests. Other relevant parameters used in the model are listed in Table 6.

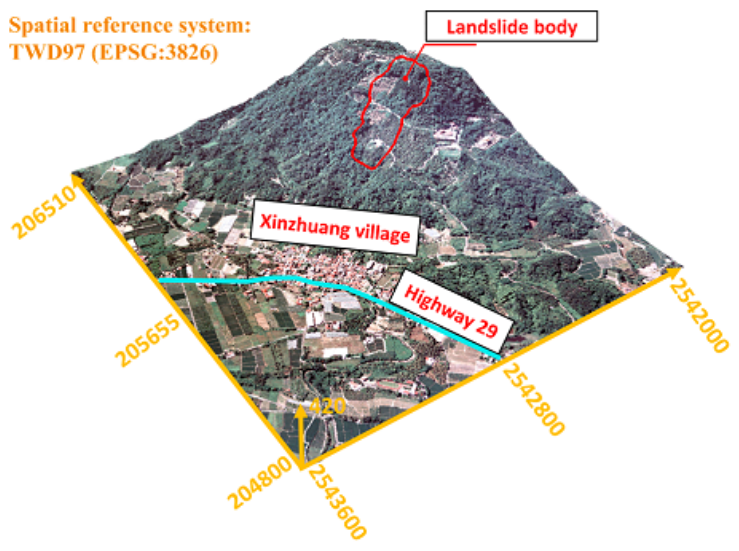

(a) Satellite image

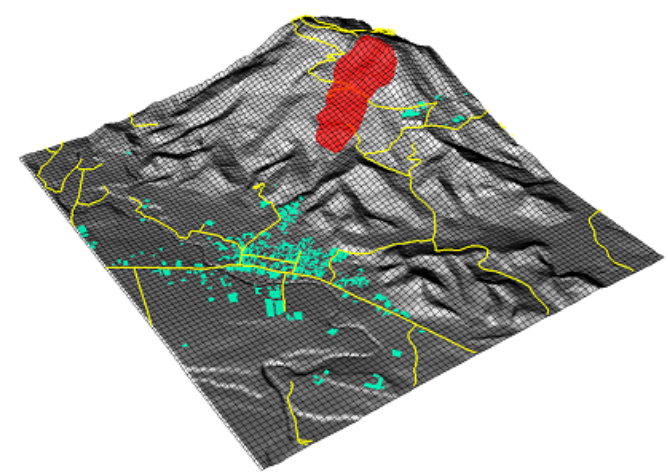

(b) Numerical models

Figure 11. Three-dimensional models of the Zone 3 potential sliding mass of the Xinzhuang landslide. (a) Satellite image; (b) Numerical models.

Table 6. Parameters used in RAMMS for the Xinzhuang landslide.

\begin{tabular}{ccc}
\hline Parameters & Laboratory Test & Numerical Simulation \\
\hline Unit weight $\left(\rho, \mathrm{kg} / \mathrm{cm}^{2}\right)$ & $2.14-2.60$ & 2.40 \\
Friction angle $(\phi, \mathrm{deg})$. & 23 & 23 \\
Friction coefficient $(\mu)$ & 0.42 & 0.42 \\
Turbulent friction coefficient $\left(\xi, \mathrm{m} / \mathrm{s}^{2}\right)$ & - & $2000^{1}$ \\
Simulation stop criteria & & $\mathrm{M}_{\max }<3 \%{ }^{2}$ \\
\hline
\end{tabular}

Note: ${ }^{1}$ Suggestion value by RAMMS manual [12] (Volume $>60,000 \mathrm{~m}^{3}$; elevation $<1000 \mathrm{~m}$ ). ${ }^{2} \mathrm{M}_{\max }$ : Maximum momentum.

The potential sliding mass defined by Zone 3 was used as the sediment source for the model. From image interpretation, the horizontal area of the landslide was determined to be $109,200 \mathrm{~m}^{2}$, and the slope area of the landslide was estimated at 141,000 $\mathrm{m}^{2}$. The mean depth of Zone 3 was assumed to be equal to $20 \mathrm{~m}$, as shown in Figure 10. The total estimated volume of the landslide was 2,820,000 $\mathrm{m}^{3}$.

Figure 12 shows the runout extent of the Zone 3 potential sliding mass after failure. The results revealed that the thickest deposit during the failure was $88 \mathrm{~m}$ (located just below Zone 2). Analysis results were overlaid with the locations of households and infrastructure to determine accumulation depths. It was found that the houses would be buried 5 to $20 \mathrm{~m}$ deep in debris. The width of the landslide deposit was $440 \mathrm{~m}$, and the total runout distance was $1250 \mathrm{~m}$. The numerical simulation showed that the highest instantaneous velocity in the upper part of the failure was $62 \mathrm{~m} / \mathrm{s}$. When the landslide reached the households, the peak velocity of the debris was approximately $18 \mathrm{~m} / \mathrm{s}$. To understand the further landslide hazard, this study included the deposition height as an assessment index from RAMMS and evaluated the landslide hazard in this case (Table 7; [53]). 


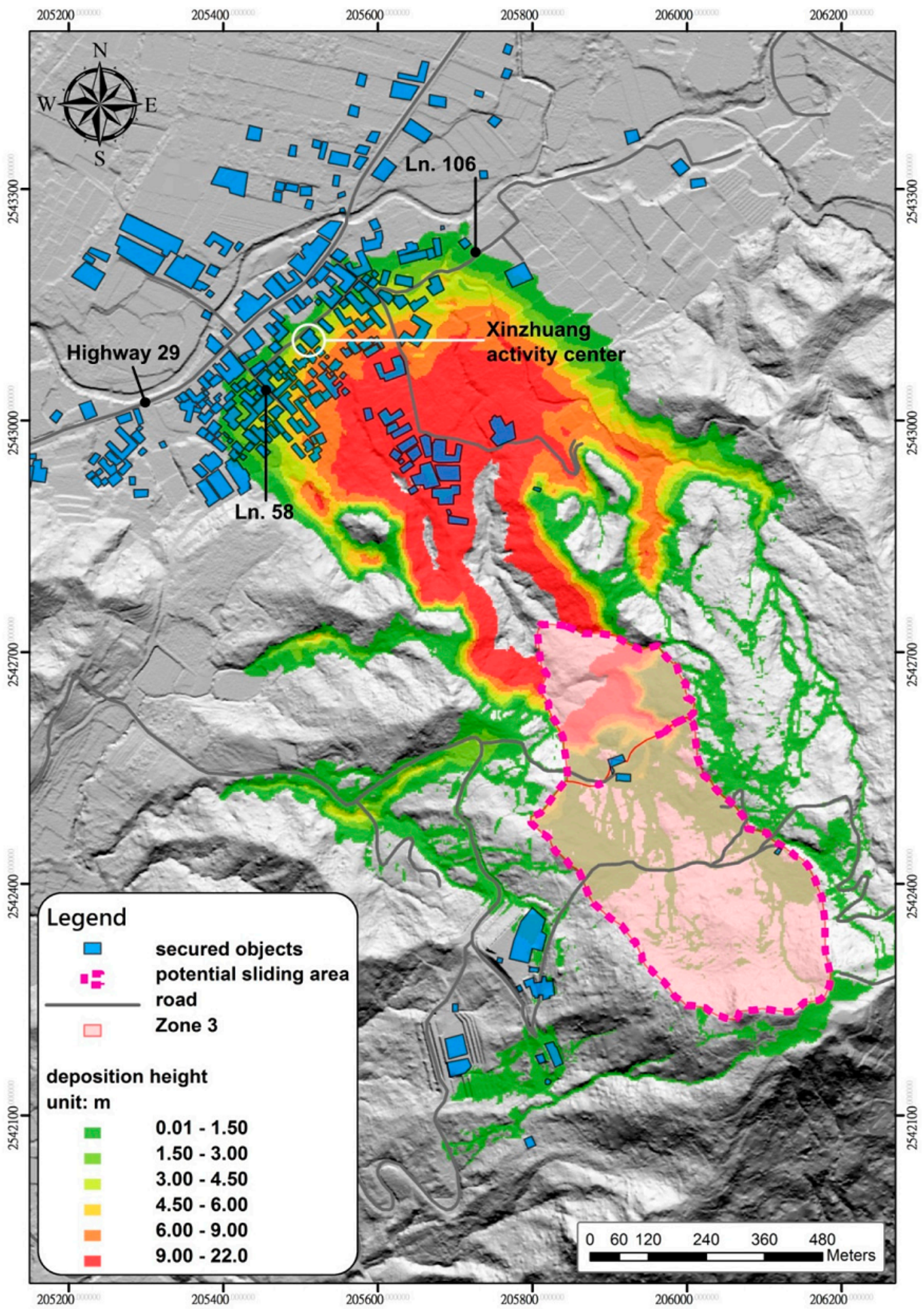

Figure 12. Influence zone and accumulation depth assuming failure of the Zone 3 potential sliding mass.

Table 7. Landslide hazard classification (revised from Hürlimann et al. [53]).

\begin{tabular}{ccc}
\hline Parameter & Deposition Height $(h)$ & Landslide Hazard \\
\hline \multirow{3}{*}{ Intensity } & $h<1.0 \mathrm{~m}$ & Low \\
& $1.0 \mathrm{~m}<h<2.5 \mathrm{~m}$ & Moderate \\
$h>2.5 \mathrm{~m}$ & High \\
\hline
\end{tabular}


The building structures in residential areas in Taiwan are mostly constructed of reinforced concrete $(\mathrm{RC})$, so the landslide velocity is not the primary factor in destroying the housing and public facilities, according to past landslide investigations. Those investigations indicated that the primary factor that affects the evacuation of residents is the flow height, so this study focuses on the flow height to assess the following evacuation plan. This approach defined three landslide hazard levels depending on the influence of sediment deposition on the building structure (Figure 13, i.e., low, moderate, and high level). The housing is also illustrated in the same color in the influence area, so that the competent authority can set up a corresponding regional disaster prevention and response plan.

If this failure occurs, the residents located close to the gully at the base of the large-scale landslide will be impacted first. Next, the debris will be directed over the flat topography in the northwest area of the landslide. In summary, over half of the residents in Xinzhuang Village are in the hazard area of the landslide and are at risk of being impacted by the landslide. Regarding road conditions, based on model results, the landslide will not influence Highway 29; only the agricultural road that leads towards Shizi Mountain will be covered by debris and impassable to vehicles. 


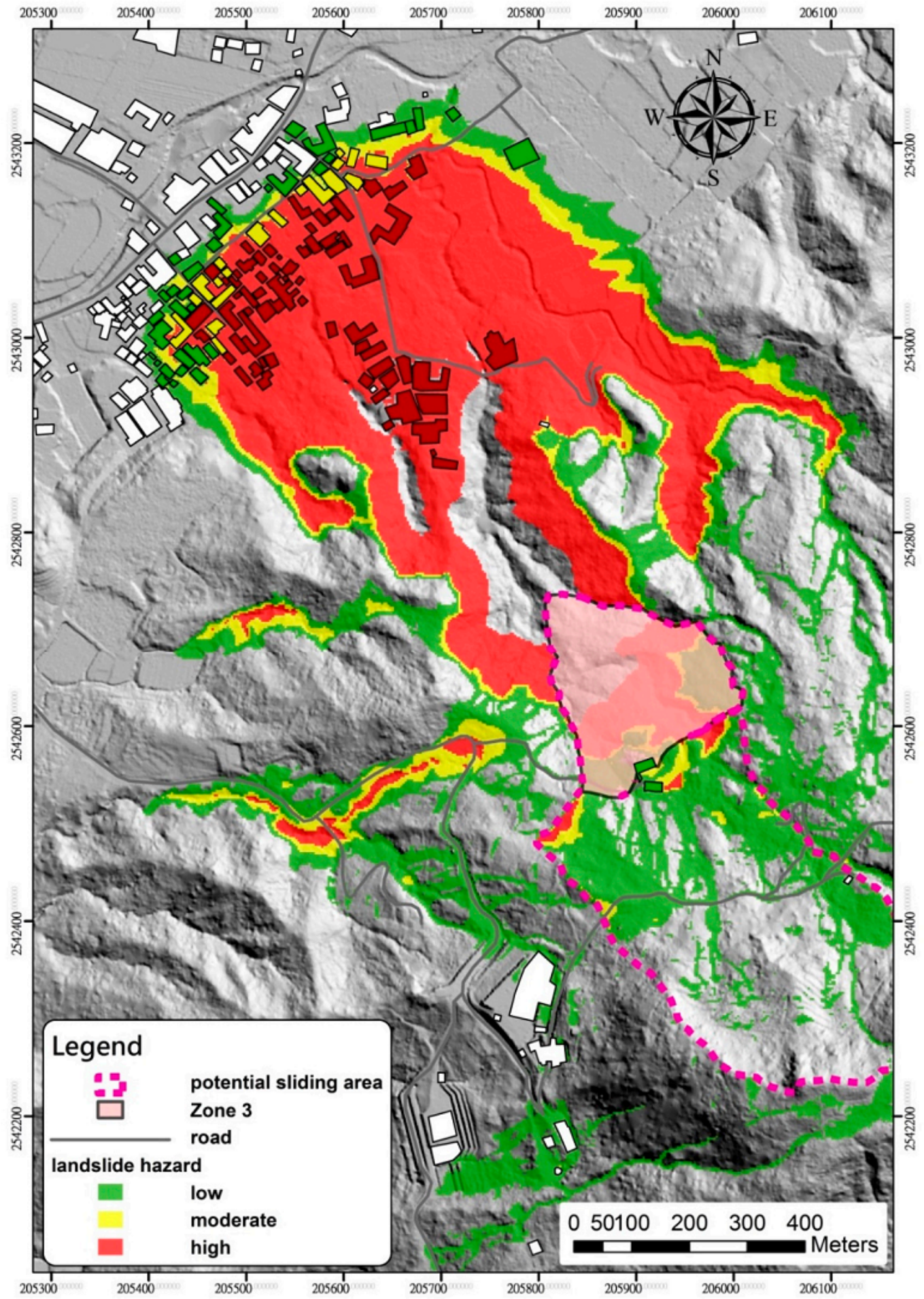

Figure 13. Landslide hazard map assuming failure of the Zone 3 potential sliding mass.

\subsection{Disaster Prevention and Evacuation Plan}

This study collected data from the Shanlin District public office "Xinzhuang residents' disaster prevention card" (November 2013), the Shanlin District "Emergency rescue center and disaster evacuation center manual" (March 2014), and the Kaohsiung City government's "List of disaster evacuation centers" (June 2014). From this information, the study found that the city government and 
district offices had already developed plans for the Xinzhuang District activity center, Xinhe District activity center, and Daai activity center to be used as evacuation centers.

To examine the suitability of the existing disaster prevention and evacuation plans for the situation of a large-scale landslide in Xinzhuang Village, the locations of the selected evacuation centers were checked against the hazard zone of the landslide and the modeled landslide runout extent (Figure 12). The Xinzhuang District activity center is located within the influence zone of the Zone 3 landslide (the accumulation depth at the activity center is predicted to be 1.0 to $4.5 \mathrm{~m}$ ). Most residents that are at risk of the landslide are located in the area bounded by the south-east area of Highway 29, Ln. 106 and Ln. 58. Because the Xinzhuang District activity center is located within a conservative estimate of the influence zone of the Zone 3 landslide, the activity center is not a suitable location for protecting human lives, and thus should not be used as an evacuation center.

The evacuation map of the Xinzhuang landslide drawn in this study is shown in Figure 14. Results suggest that the Xinhe District activity center and the Daai activity center can be safely used as evacuation centers for residents in the hazard zone. Moreover, evacuees can follow Highway 29 to the north for approximately $1.6 \mathrm{~km}$ to reach the Xinhe District activity center. That activity center has a capacity of 30 people. Evacuees can also head south on Highway 20 for $4.2 \mathrm{~km}$ to reach the Daai activity center. The capacity of the Daai activity center is 100 people.

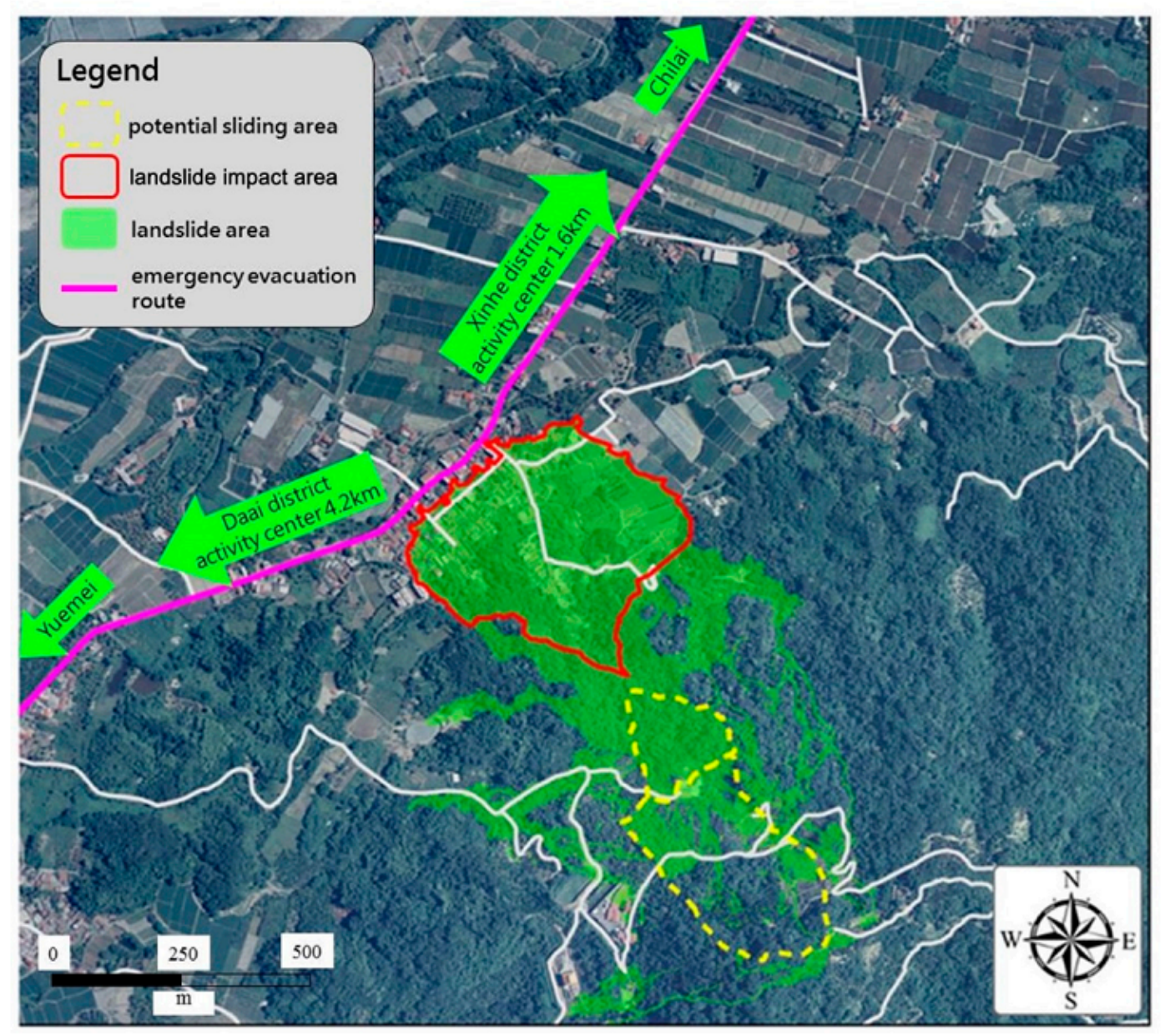

Figure 14. Evacuation map for the Xinzhuang landslide.

If only two evacuation centers are available, only 130 people can be accommodated. The capacity of the two evacuation centers is insufficient to accommodate the 119 households or 360 people that could be affected by the large-scale landslide. Therefore, this study suggests that the district and city 
governments add another evacuation center and update the district disaster prevention and response plans for the area.

\subsection{Discussion}

This study compiled current methods for investigating and evaluating large-scale landslides. Each method has a specific purpose and application. The method should be selected based on project goals, funding, and scheduling. Before implementing the investigation and evaluation, a proper plan is needed to ensure that project goals are achieved or exceeded.

The investigation phase produced two key findings: (1) The interpretation of high-resolution DEM and landslide micro-topography is an important component of the analytical procedure. The results can be used to partition the locations and areas of potential sliding masses in the study area and serve as a basis for subsequent geological drilling and geophysical exploration configuration planning. (2) Geological drilling, geophysical prospecting, and in-situ or laboratory tests are basic and necessary tasks. For potential large-scale landslides, several factors must to be noted: (a) geological drilling must penetrate into the deepest slip surface or bedrock and should not be less than $30 \mathrm{~m}$; (b) the RIP method can be used for geophysical prospecting (seismic methods are recommended for shallow landslides), the prospecting line should match the geological drilling position, and the prospecting depth must exceed the depth of the geological drilling; and (c) all hydrogeological units should obtain the physical, mechanical, and hydrological parameters.

The assessment phase produced two key findings: (1) GeoStudio and RAMMS were used to assess the potential and influence zones of a large-scale landslide. Slope stability analysis can be used to analyze the scenario conditions for possible failure through scenario simulation. It is recommended that subsequent analysis of the landslide impact zone be conducted for analysis results that do not meet the specifications. The volume of the landslide can be assessed by landslide micro-topography interpretation (area) and slope stability analysis (depth), and even three-dimensional slope stability analysis can be used. (2) The observation period of this study was only three months. If long-term observation data (such as over one year) are available, it is suggested that rainfall infiltration-groundwater seepage-slope stability analysis be considered. Such an analysis would allow further discussion of the correlations among rainfall, water table, and safety factor at different return periods.

\section{Conclusions}

1. This paper integrates existing survey techniques and analysis models. The purpose of the field investigation is to understand the environmental conditions contributing to slope instability, the extent and volume of the landslide, and the people and infrastructure affected by the landslide hazard. The purpose of the assessment is to understand the stability of the landslide mass, its failure mode, the failure extent and the sensitivity of the landslide to earthquakes and torrential rain.

2. Furthermore, the paper presents an analytical procedure that can be applied to assess the possible impact of the landslide collapse on nearby settlements. The GeoStudio and RAMMS analysis modes and the hazard classification can be used to estimate the following: (a) the failure mechanism and the influence zone of large-scale landslides; (b) the migration and accumulation of failure; (c) the landslide hazard map and evacuation map. The analytical procedure can be applied to other villages and used as a reference for the development of disaster prevention and evacuation plans.

3. The paper employs the Xinzhuang landslide as an example to illustrate how to perform this analytical procedure. After completing a comprehensive analysis of the Xinzhuang landslide, the landslide was divided into three potential failure masses (Zone 1, Zone 2 and Zone 3). Analytical results showed that the potential failure block (Zone 3) could become unstable under earthquake conditions. If the Zone 3 potential sliding mass does mobilize, the main area affected 
by the deposit is the area southeast of Highway 29, Ln. 106 and Ln. 58. People living in this area are at risk of being buried by 1 to $20 \mathrm{~m}$ of landslide debris (deeper than the adjacent deposit visible at the foot of Shizi Mountain).

4. The methods used to evaluate the failure scenario and landslide scale are very important. The methods proposed in this paper, landslide micro-topography and slope stability analysis, should be relatively simple methods. Furthermore, RAMMS can estimate the impact area and accumulation depth after failure, with hazard classification, and this information can be included in the landslide hazard map. The analytical results can be used to assess the extent of the landslide threat and to check the suitability of the disaster prevention and evacuation plan.

Author Contributions: This paper represents a result of collaborative teamwork. M.-C.C. conceived the entire paper, checked the calculation results, and revised the manuscript. C.-H.C. performed the slope stability analysis and drafted the manuscript. C.-F.L. performed the landslide hazard analysis and revised the manuscript. W.-K.H. discussed the composition of the manuscript. C.-H.T. provided constructive suggestions both for technical and manuscript preparation. All authors significantly contributed to the research.

Acknowledgments: This work was supported by the Soil and Water Conservation Bureau, Council of Agriculture, Executive Yuan (SWCB) (Grant No. 1030818053A). The authors are especially thankful to the Su-Chin Chen, the dean of the Soil and Water Conservation Department at National Chung Hsing University. Su-Chin Chen was very helpful throughout this study. Finally, to all of the agencies and colleagues at Sinotech, Inc., we express our gratitude for their support and hard work.

Conflicts of Interest: The authors declare no conflicts of interest.

\section{References}

1. Varnes, D.J. Slope movement types and processes. In Special Report 176: Landslides: Analysis and Control; Schuster, R.L., Krizek, R.J., Eds.; Transportation and Road research board; National Academy of Science: Washington, DC, USA, 1978; pp. 11-33.

2. Cruden, D.M.; Varnes, D.J. Landslides: Investigation and Mitigation, Chapter 3: Landslide Types and Processes; Transportation Research Board Special Report; National Academy of Science: Washington, DC, USA, 1996.

3. Soeters, R.; van Westen, C.J. Landslides: Investigation and mitigation. Trans. Res. Board Spec. Rep. 1996, 247, 129-177.

4. Agliardi, F. Structural constraints on deep-seated slope deformation kinematics. Eng. Geol. 2001, 59, 83-102. [CrossRef]

5. Chigira, M. Geological and geomorphological characteristics of deep-seated catastrophic landslides induced by rain and earthquakes. J. Chin. Soil Water Conserv. 2011, 42, 265-278.

6. Lin, M.L.; Chen, T.W.; Lin, C.W.; Ho, D.J.; Cheng, K.P.; Yin, H.Y.; Chen, M.C. Detecting large-scale landslides using lidar data and aerial photos in the Namasha-Liuoguey area, Taiwan. Remote Sens. 2014, 6, 42-63. [CrossRef]

7. Lo, C.M. Evolution of deep-seated landslide at Putanpunas stream, Taiwan. Geomat. Nat. Hazards Risk 2017, 8, 1204-1224. [CrossRef]

8. National Science and Technology Center for Disaster Reduction (NCDR). Disaster Survey and Analysis of Morakot Typhoon; National Science Council: Taipei, Taiwan, 2010; pp. 12-25. (In Chinese)

9. Central Geological Survey (CGS). Official Report: Project of Investigation and Analysis for Geologically Sensitive Areas under the Program of National Land Preservation-Geological Susceptability Analysis in Damage Area Struck by Morakot Typhoon; CGS: Taipei, Taiwan, 2010-2012. (In Chinese)

10. Central Geological Survey (CGS). Official Report: Project of Investigation and Analysis for Geologically Sensitive Areas under the Program of National Land Preservation-Geological Susceptability Analysis in Areas Left Intact by Morakot Typhoon; CGS: New Taipei, Taiwan, 2013-2015. (In Chinese)

11. GEO-SLOPE. Stability Modeling with SLOPE/W: An Engineering Methodology July 2012 Edition; GEO-SLOPE International Ltd.: Calgary, AB, Canada, 2012.

12. SLF/WSL. RAMMS: User Manual v1.5. Avalanche, a Numerical Model for Snow Avalanches in Research and Practice; SLF/WSL: Davos, Switzerland, 2013; 97p. 
13. Bichler, A.; Bobrowsky, P.; Best, M.; Douma, M.; Hunter, J.; Calvert, T.; Burns, R. Three-dimensional mapping of a landslide using a multi-geophysical approach: The Quesnel Forks landslide. Landslides 2004, 1, $29-40$. [CrossRef]

14. Booth, A.M.; Roering, J.J.; Perron, J.T. Automated landslide mapping using spectral analysis and high-resolution topographic data: Puget Sound lowlands, Washington, and Portland Hills, Oregon. Geomorphology 2009, 109, 132-147. [CrossRef]

15. Lahousse, T.; Chang, K.T.; Lin, Y.H. Landslide mapping with multi-scale object-based image analysis-A case study in the Baichi watershed, Taiwan. Nat. Hazards Earth Syst. Sci. 2011, 11, 2715-2726. [CrossRef]

16. Hölbling, D.; Betts, H.; Spiekermann, R.; Phillips, C. Identifying spatio-temporal landslide hotspots on North Island, New Zealand, by analyzing historicaland recent aerial photography. Geosciences 2016, 6, 48. [CrossRef]

17. Lee, C.F.; Lo, C.M.; Chou, H.T.; Chi, S.Y. Landscape evolution analysis of large scale landslides at Don-Ao Peak, Taiwan. Environ. Earth Sci. 2016, 75, 29. [CrossRef]

18. Central Geological Survey (CGS). Official Report: Investigation and Analysis for Geologically Sensitive Area in National Preservation Domain Program; CGS: Taipei, Taiwan, 2012. (In Chinese)

19. Chigira, M. September 2005 rain-induced catastrophic rockslides on slopes affected by deep-seated gravitational deformations, Kyushu, southern Japan. Eng. Geol. 2009, 108, 1-15. [CrossRef]

20. Sekiguchi, T.; Sato, H.P. Mapping of micro topography using airborne laser scanning. Landslides 2004, 1, 195-202. [CrossRef]

21. Yoshimatsu, H.; Abe, S. A review of landslide hazards in Japan and assessment of their susceptibility using an analytical hierarchic process (AHP) method. Landslides 2006, 3, 149-158. [CrossRef]

22. Lee, C.F.; Huang, W.K.; Chang, Y.L.; Chi, S.Y.; Liao, W.C. Regional landslide susceptibility assessment using multi-stage remote sensing data along the coastal range highway in northeastern Taiwan. Geomorphology 2018, 300, 113-127. [CrossRef]

23. Chung, M.C.; Tan, C.H.; Chen, C.H. Local rainfall thresholds for forecasting landslide occurrence: Taipingshan landslide triggered by Typhoon Saola. Landslides 2017, 14, 19-33. [CrossRef]

24. Gregory, J.H.; Dukes, M.D.; Miller, G.L.; Jones, P.H. Analysis of double-ring infiltration techniques and development of a simple automatic water delivery system. Appl. Turfgrass Sci. 2005. [CrossRef]

25. Jongmans, D.; Garambois, S. Geophysical investigation of landslides: A review. Bull. Soc. Géol. Fr. 2007, 178, 101-112. [CrossRef]

26. Gelisli, K.; Ersoy, H. Landslide investigation with the use of geophysical methods: A case study in northeastern Turkey. Adv. Biol. Earth Sci. 2017, 2, 52-64.

27. Lau, K.C. A Review of Downhole Geophysical Methods for Ground Investigation; Geotechnical Engineering Office: Hong Kong, China, 1998; 69p.

28. Lo, H.C.; Chou, P.Y.; Hsu, S.M.; Chao, C.H.; Wang, C.T. Using borehole prospecting technologies to determine the correlation between fracture properties and hydraulic conductivity: A case study in Taiwan. J. Environ. Eng. Geophys. 2012, 17, 27-37. [CrossRef]

29. Braester, C.; Thunvik, R. Determination of formation permeability by double-packer tests. J. Hydrol. 1984, 72, 375-389. [CrossRef]

30. Lins, Y.; Schanz, T.; Fredlund, D.G. Modified Pressure Plate Apparatus and Column Testing Device for Measuring SWCC of Sand. Geotech. Test. J. 2009, 32, 1-15.

31. Chen, Z.Y.; Shao, C.M. Evaluation of minimum factor of safety in slope stability analysis. Can. Geotech. J. 1988, 25, 735-748. [CrossRef]

32. Pourkhosravani, A.; Kalantari, B. A review of current methods for slope stability evaluation. Electron. J. Geotech. Eng. 2011, 16, 1245-1254.

33. Kainthola, A.; Verma, D.; Thareja, R.; Singh, T.N. A review on numerical slope stability analysis. Int. J. Sci. Eng. Technol. Res. 2013, 2, 1315-1320.

34. Berisavljević, Z.; Berisavljević, D.; Čebašek, V.; Rakić, D. Slope stability analyses using limit equilibrium and strength reduction methods. Građevinar 2015, 67, 975-983.

35. Jeong, S.; Lee, K.; Kim, J.; Kim, Y. Analysis of rainfall-induced landslide on unsaturated soil slopes. Sustainability 2017, 9, 1280. [CrossRef]

36. Gol, M.D.; Keykha, H.A.; Rahnama-Rad, J. Assessment slope stability based on deformation of rock joints and soil with simulation method. Open J. Geol. 2016, 6, 983-995. [CrossRef] 
37. Länsivaara, T.; Poutanen, T. Slope stability with partial safety factor method. In Proceedings of the 18 th International Conference on Soil Mechanics and Geotechnical Engineering, Challenges and Innovations in Geotechnics, Paris, France, 2-5 September 2013.

38. Abramson, L.W.; Lee, T.S.; Sharma, S.S.; Boyce, G.M. Slope Stability and Stabilization Methods, 2nd ed.; John Wiley and Sons Ltd.: New York, NY, USA, 2001; ISBN 978-0-471-38493-9.

39. Fredlund, D.G.; Morgenstern, N.R.; Widger, R.A. The shear strength of unsaturated soils. Can. Geotech. J. 1978, 12, 313-321. [CrossRef]

40. Lateltin, O.; Haemmig, C.; Raetzo, H.; Bonnard, C. Landslide risk management in Switzerland. Landslides 2005, 2, 313-320. [CrossRef]

41. Jaboyedoff, M.; Dudt, J.P.; Labiouse, V. An attempt to refine rockfall hazard zoning based on the kinetic energy, frequency and fragmentation degree. Nat. Hazards Earth Syst. Sci. 2005, 5, 621-632. [CrossRef]

42. Lo, C.M.; Lee, C.F.; Chou, H.T.; Lin, M.L. Landslide at Su-Hua Highway 115.9k triggered by Typhoon Megi in Taiwan. Landslides 2013, 11, 293-304. [CrossRef]

43. Llano-Serna, M.A.; Farias, M.M.; Pedroso, D.M. An assessment of the material point method for modelling large scale run-out processes in landslides. Landslides 2016, 13, 1057-1066. [CrossRef]

44. Eberhardt, E. Rock Slope Stability Analysis: Utilization of Advanced Numerical Techniques; Earth and Ocean Sciences, University of British Columbia: Vancouver, BC, Canada, 2003; 41p.

45. Voellmy, A. On the Destructive Force of Avalanches; SLF: Davos, Switzerland, 1955; pp. 159-162.

46. Salm, B. Flow, flow transition and runout distances of flowing avalanches. Ann. Glaciol. 1993, 18, $221-226$. [CrossRef]

47. Wu, C.H.; Chen, S.C.; Chou, H.T. Geomorphologic characteristics of catastrophic landslides during typhoon Morakot in the Kaoping Watershed, Taiwan. Eng. Geol. 2011, 123, 13-21. [CrossRef]

48. Tsou, C.Y.; Feng, Z.Y.; Chigira, M. Catastrophic landslide induced by typhoon Morakot, Shiaolin, Taiwan. Geomorphology 2011, 127, 25-42. [CrossRef]

49. Lee, C.F.; Huang, W.K.; Huang, C.M.; Chi, C.C. Deep-seated landslide mapping and geomorphic characteristic using high resolution DTM in northern Taiwan. In Workshop on World Landslide Forum; Springer: Cham, Switzerland, 2017; pp. 767-777.

50. Lo, C.M.; Lee, C.F.; Keck, J. Application of sky view factor technique to the interpretation and reactivation assessment of landslide activity. Environ. Earth Sci. 2017, 76, 375. [CrossRef]

51. Construction and Planning Agency. Seismic Design Specifications and Commentary of Buildings; Construction and Planning Agency, Ministry of the Interior: Taipei, Taiwan, 2011.

52. Soil and Water Conservation Bureau (SWCB). Technical Regulations for Soil and Water Conservation; SWCB, Council of Agriculture: Nantou, Taiwan, 2014.

53. Hürlimann, M.; Rickenmann, D.; Medina, V.; Bateman, A. Evaluation of approaches to calculate debris-flow parameters for hazard assessment. Eng. Geol. 2008, 102, 152-163. [CrossRef] 